\title{
EANM procedural guidelines for PET/CT quantitative myocardial perfusion imaging
}

\author{
Roberto Sciagrà ${ }^{1}$ (1) - Mark Lubberink ${ }^{2,3} \cdot$ Fabien Hyafil $^{4,5}$ • Antti Saraste ${ }^{6,7} \cdot$ Riemer H. J. A. Slart $^{8,9} \cdot$ Denis Agostini $^{10}$ • \\ Carmela Nappi ${ }^{11}$. Panagiotis Georgoulias ${ }^{12}$. Jan Bucerius ${ }^{13} \cdot$ Christoph Rischpler $^{14}$ • Hein J. Verberne ${ }^{15}$. \\ Cardiovascular Committee of the European Association of Nuclear Medicine (EANM)
}

Received: 18 August 2020 / Accepted: 17 September 2020 / Published online: 2 November 2020

(C) The Author(s) 2020

\begin{abstract}
The use of cardiac PET, and in particular of quantitative myocardial perfusion PET, has been growing during the last years, because scanners are becoming widely available and because several studies have convincingly demonstrated the advantages of this imaging approach. Therefore, there is a need of determining the procedural modalities for performing high-quality studies and obtaining from this demanding technique the most in terms of both measurement reliability and clinical data. Although the field is rapidly evolving, with progresses in hardware and software, and the near perspective of new tracers, the EANM Cardiovascular Committee found it reasonable and useful to expose in an updated text the state of the art of quantitative myocardial perfusion PET, in order to establish an effective use of this modality and to help implementing it on a wider basis. Together with the many steps necessary for the correct execution of quantitative measurements, the importance of a multiparametric approach and of a comprehensive and clinically useful report have been stressed.
\end{abstract}

Keywords PET $\cdot$ Myocardial blood flow · Myocardial flow reserve $\cdot$ Quantitative imaging

This article is part of the Topical Collection on Cardiology

These procedural guidelines are dedicated in memory of Prof. Eugenio Inglese, founding father of the Italian Group of Nuclear Cardiology and victim of COVID-19.

Roberto Sciagrà

roberto.sciagra@unifi.it

1 Nuclear Medicine Unit, Department of Experimental and Clinical Biomedical Sciences "Mario Serio", University of Florence, Largo Brambilla 3, 50134 Florence, Italy

2 Radiology \& Molecular Imaging, Department of Surgical Sciences, Uppsala University, Uppsala, Sweden

3 Medical Physics, Uppsala University Hospital, Uppsala, Sweden

4 Department of Nuclear Medicine, DMU IMAGINA, APHP, Hôpital Européen Georges-Pompidou, University of Paris, Paris, France

5 Université de Paris, PARCC, INSERM 690, Paris, France

6 Turku PET Centre, Turku University Hospital, University of Turku, Turku, Finland

7 Heart Center, Turku University Hospital, Turku, Finland
8 Department of Nuclear Medicine and Molecular Imaging, University Medical Center Groningen, Groningen, The Netherlands

9 Faculty of Science and Technology Biomedical, Photonic Imaging, University of Twente, Enschede, The Netherlands

10 Department of Nuclear Medicine, CHU Cote de Nacre, Normandy University, EA 4650, Caen, France

11 Department of Advanced Biomedical Sciences, University Federico II, Naples, Italy

12 Department of Nuclear Medicine, Faculty of Medicine, University of Thessaly, University Hospital of Larissa, Larissa, Greece

13 Department of Nuclear Medicine, University Medicine Göttingen, Georg-August University Göttingen, Göttingen, Germany

14 Department of Nuclear Medicine, University Hospital Essen, University of Duisburg-Essen, Essen, Germany

15 Department of Radiology and Nuclear Medicine, Amsterdam UMC, location AMC, University of Amsterdam, Amsterdam, The Netherlands 


\section{Preamble}

The European Association of Nuclear Medicine (EANM) is a professional non-profit medical association that facilitates communication worldwide among individuals pursuing clinical and research excellence in nuclear medicine. The EANM was founded in 1985. These guidelines are intended to assist practitioners in providing appropriate nuclear medicine care for patients. They are not inflexible rules or requirements of practice and are not intended, nor should they be used, to establish a legal standard of care. The ultimate judgement regarding the propriety of any specific procedure or course of action must be made by medical professionals taking into account the unique circumstances of each case. Thus, there is no implication that an approach differing from the guidelines, standing alone, is below the standard of care. To the contrary, a conscientious practitioner may responsibly adopt a course of action different from that set out in the guidelines when, in the reasonable judgement of the practitioner, such course of action is indicated by the condition of the patient, limitations of available resources or advances in knowledge or technology subsequent to publication of the guidelines. The practice of medicine involves not only the science but also the art of dealing with the prevention, diagnosis, alleviation and treatment of disease. The variety and complexity of human conditions make it impossible to always reach the most appropriate diagnosis or to predict with certainty a particular response to treatment. Therefore, it should be recognised that adherence to these guidelines will not ensure an accurate diagnosis or a successful outcome. All that should be expected is that the practitioner will follow a reasonable course of action based on current knowledge, available resources and the needs of the patient to deliver effective and safe medical care. The sole purpose of these guidelines is to assist practitioners in achieving this objective.

\section{Introduction-rationale}

The use of PET (positron emission tomography) tracers for myocardial perfusion imaging (MPI) began in the 1980s [1]. Already in those very early years, together with the visual assessment of the uptake pattern, quantitative methods for measuring myocardial blood flow (MBF) were proposed and developed [2-5]. However, due to logistic constraints caused by the high costs of imaging systems and the limited availability of on-site cyclotrons needed for the production of then available perfusion tracers with short half-lives, myocardial perfusion PET was restricted to few research centres. Recently, the exponential growth of PET imaging in oncology has led to a major increase in the number of installed PET scanners. In addition, the availability of PET perfusion radiotracers that do not require an on-site cyclotron, such as (generator-based) Rubidium-82 $\left({ }^{82} \mathrm{Rb}\right)$ or new Fluorine-18 $\left({ }^{18} \mathrm{~F}\right)$-labelled radiotracers, is likely to increase in Europe in the coming years. Combined, these factors have increased the accessibility of PET MPI and have revived the interest in PET as a modality for the quantitative assessment of myocardial perfusion. Nevertheless, the acquisition and analysis of quantitative PET MPI is demanding and requires a high level of expertise.

The objectives of these guidelines are to promote the standardisation of acquisition protocols for quantitative PET MPI and propose up-to-date diagnostic criteria for the interpretation of PET MPI. In addition, these guidelines provide some insights into the clinical applications of quantitative PET MPI.

\section{PET technology}

\section{PET imaging systems}

Dynamic cardiac PET is probably the most demanding protocol in terms of PET acquisition. During the first pass through the heart, the entire injected radioactivity is inside the field of view of the scanner, resulting in very high count rates. A few minutes later, both the short half-lives of especially Oxygen$15\left({ }^{15} \mathrm{O}\right)$ and ${ }^{82} \mathrm{Rb}$ and the distribution of the radioactivity throughout the entire body result in very low count rates. To put this in perspective, the amount or radioactivity within the field of view of the scanner is 20-40 times higher during the first pass in a dynamic scan than during a typical whole-body $\left[{ }^{18} \mathrm{~F}\right]$-fluorodeoxyglucose $\left(\left[{ }^{18} \mathrm{~F}\right] \mathrm{FDG}\right)$ scan, whereas at the end of the dynamic scan, it is about a factor 100 lower, approximately between 25 and $50 \%$ of that in a whole-body $\left[{ }^{18} \mathrm{~F}\right] \mathrm{FDG}$ scan. Figure 1 illustrates the noise-equivalent count (NEC) rate capabilities of different types of PET scanners, the properties of which will be discussed in further detail in the paragraphs below.

\section{D vs. 3D}

In a 2-dimensional (2D) PET scanner, detector rings are separated by septa (e.g. lead or tungsten rings). These septa partially shield coincidences from occurring between detectors in one ring and detectors in a non-adjacent or more distant rings and will reduce scattered events. A scanner without septa is referred to as a 3-dimensional (3D) scanner. This 3D mode allows for coincidences between all available rings, significantly increasing sensitivity and count rate per detector, but on the other hand increasing scatter and randoms as well. However, the advantages due to improved sensitivity far outweigh the disadvantages due to increased scatter and randoms (Fig. 1). The latest generations of PET/computed tomography (CT) scanners are no longer equipped with septa, because 


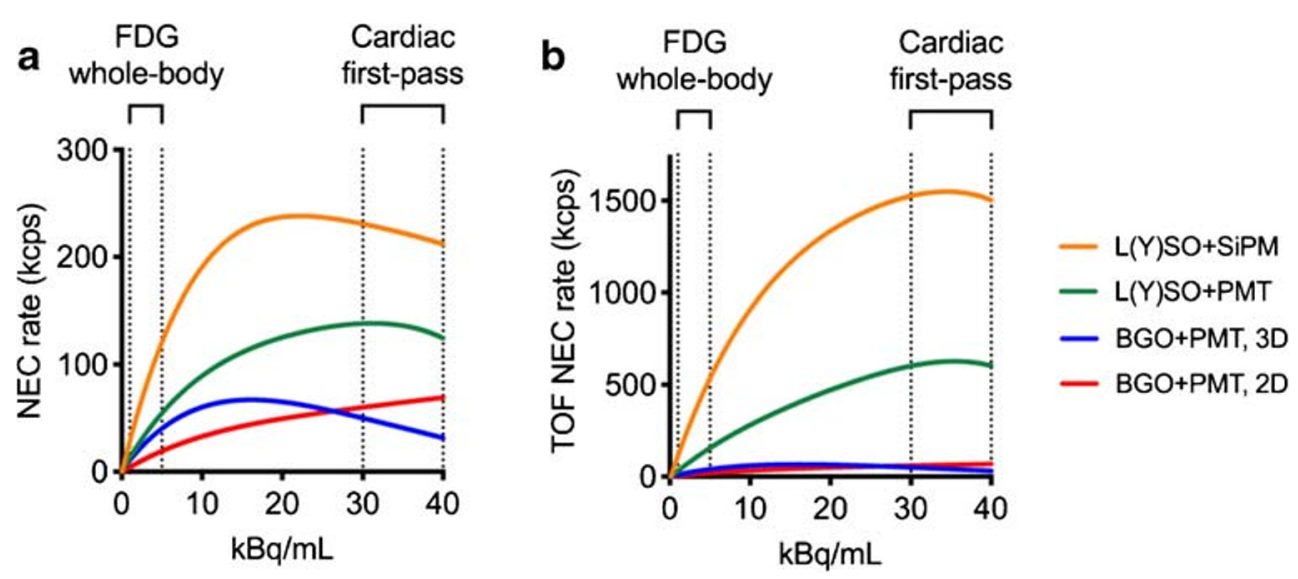

Fig. 1 Typical noise-equivalent count (NEC) rate curves. $\mathrm{BGO}=$ bismuth germanate, $\mathrm{GSO}=$ gadolinium oxyorthosilicate, $\mathrm{LSO}=$ lutetium oxyorthosilicate, LYSO = lutetium-yttrium oxyorthosilicate, PMT = photomultiplier, SIPM = silicon photomultiplier. a NEC rates. $\mathbf{b}$ NEC rates accounting for image quality improvements due to time of flight.

improved detector technology and faster electronics allow for better handling of high count rates, and increased computing power and current reconstruction algorithms allow to deal with the much larger amounts of raw data produced in $3 \mathrm{D}$ PET [6].

\section{Crystals}

The most common crystal types applied in PET are BGO (bismuth germanate), GSO (gadolinium oxyorthosilicate), and the lutetium-based crystals, such as LSO (lutetium oxyorthosilicate) and LYSO (lutetium-yttrium oxyorthosilicate). Each type of crystal has been used for cardiac imaging. Table 1 gives an overview of some important properties of these crystals. Using BGO, NEC rates are higher in $2 \mathrm{D}$ mode than in $3 \mathrm{D}$ mode during the first pass of PET tracer during a dynamic cardiac scan (Fig. 1a). This is the reason why cardiac PET was preferably done in 2D mode on older scanners. As also seen in Table 1 and Fig. 1a, LSO and LYSO detectors, because of their shorter light decay time combined with fast electronics, allow for higher count rates, resulting in much higher 3D mode NEC rates during cardiac first-pass imaging than BGO.

Table 1 Properties of commonly used crystals for PET scanners

\begin{tabular}{lllll}
\hline & BGO & GSO & LSO & LYSO \\
\hline Density $\left(\mathrm{g} / \mathrm{cm}^{3}\right)$ & 7.1 & 6.7 & 7.4 & 7.4 \\
Attenuation length (mm) & 10.4 & 14.1 & 11.4 & 11.8 \\
Light output (photons/MeV) & 9000 & 8000 & 30,000 & 30,000 \\
Light decay time (ns) & 300 & 60 & 40 & 40 \\
\hline
\end{tabular}

$B G O=$ bismuth germanate, $G S O=$ gadolinium oxyorthosilicate, $L S O=$ lutetium oxyorthosilicate, $L Y S O=$ lutetium-yttrium oxyorthosilicate

Typical count rate ranges during the first pass of a dynamic acquisition over the heart, as well as during a routine whole-body $\left[{ }^{18} \mathrm{~F}\right] \mathrm{FDG}$ scan, are indicated. b The advantage of modern LYSO+SiPM scanners during first-pass imaging compared with BGO systems is clearly shown

\section{Time-of-flight}

Time-of-flight (TOF) capability can increase the signal to noise ratio of the images $[7,8]$. Figure $1 \mathrm{~b}$ shows NEC rates taking the gain due to TOF into account as well, but this is valid only for the NEMA NEC measurement with a $20-\mathrm{cm}$ phantom $[9,10]$. TOF benefits in a clinical cardiac scan are lower than what is shown here, but also in a clinical situation TOF will result in a considerable increase in signal to noise ratio compared with non-TOF reconstructions [11]. In this regard, TOF can improve image quality in cardiac perfusion imaging [12].

\section{Solid-state scanners}

Until recently, most PET systems were equipped with photomultiplier tubes (PMT) to convert the light from the scintillating crystals into an electronic pulse. The advent of PET-magnetic resonance (MR) mandated the development of new technologies, since PMTs do not work well in a magnetic field. In the latest generation of PET scanners, PMTs have been replaced by silicon photomultipliers (SiPM), either in a traditional block detector configuration, coupling an array of crystals to a smaller number of SiPMs, or coupled one-toone to scintillating crystals ('direct photon counting'). Digital PET systems allow for better TOF resolution and improved sensitivity (in case of block configurations), further improving image quality [13-15]. This is shown in Fig. 1b, stressing the advantages of last generation PET systems with SiPMs and high-efficiency TOF in terms of count rate performance during first pass in dynamic scans. So far, there are no available data about the specific advantages for quantitative cardiac PET. However, computation of parametric MBF images, showing MBF rather than just tracer uptake at the voxel level, 
requires good count statistics, and thus, the digital scanners with their improved count rate capabilities are helpful.

\section{Radiopharmaceuticals for myocardial perfusion imaging with PET (Table 2)}

\section{$\left[{ }^{15}\right.$ O]water}

$\left[{ }^{15} \mathrm{O}\right]$ water PET is considered the reference for non-invasive in vivo measurement of MBF because it is metabolically inert and essentially freely diffusible and has an extraction fraction close to one up to very high flow values (Fig. 2) $[3,18]$. The $122 \mathrm{~s}$ radioactive half-life of ${ }^{15} \mathrm{O}$ implies that $\left[{ }^{15} \mathrm{O}\right]$ water can only be used at hospitals with an on-site cyclotron. ${ }^{15} \mathrm{O}$ is produced either by irradiating enriched Nitrogen-15 $\left({ }^{15} \mathrm{~N}\right)$ with protons, using the ${ }^{15} \mathrm{~N}(\mathrm{p}, \mathrm{n}){ }^{15} \mathrm{O}$ reaction, or by irradiating natural nitrogen with deuterons using the ${ }^{14} \mathrm{~N}(\mathrm{~d}, \mathrm{n}){ }^{15} \mathrm{O}$ reaction. The advantage of the latter production method is that the target material is basically air and, hence, cheap and that the required deuteron energy is only $3 \mathrm{MeV}$, allowing for construction of small, dedicated cyclotrons requiring limited shielding, at a considerably lower cost than regular PET cyclotrons [19]. These cyclotrons have until now only been installed at a few mainly research hospitals, but their wider spread could facilitate an increased clinical use of $\left[{ }^{15} \mathrm{O}\right]$ water. Using the $(\mathrm{p}, \mathrm{n})$ reaction allows for production of $\left[{ }^{15} \mathrm{O}\right]$ water on standard medical cyclotrons. The maximum positron energy of ${ }^{15} \mathrm{O}$ of 1.7 MeV is higher than that of ${ }^{13} \mathrm{~N}$, but considerably lower than for ${ }^{82} \mathrm{Rb}$, leading to a spatial resolution somewhere in between that of ${ }^{13} \mathrm{~N}$ and ${ }^{82} \mathrm{Rb}$ [20]. In the setting of highresolution PET scanners (FWHM $=3 \mathrm{~mm}$ ), the resolution loss could be estimated to be around $0.5 \mathrm{~mm}$ [21]. Although the properties of $\left[{ }^{15} \mathrm{O}\right]$ water imply that perfusion can be measured accurately irrespective of metabolic status, a challenge associated with its freely diffusible nature is that the tracer is not retained in the myocardium. No static uptake images can be acquired to give an initial, qualitative image indicating perfusion defects or myocardial viability. Tracer kinetic modelling is required to get absolute perfusion values, and meaningful perfusion images can only be obtained by performing this modelling on a voxel level. On the other hand, the free diffusibility of $\left[{ }^{15} \mathrm{O}\right]$ water allowed for the introduction of the perfusable tissue fraction (PTF) concept, an intrinsic partial volume correction, the mathematical details of which are described in the "Quantification of myocardial blood flow", $\left[{ }^{15} \mathrm{O}\right]$ water" section [22]. This is a major difference with other perfusion agents: MBF measurements based on ${ }^{82} \mathrm{Rb}$ or $\left[{ }^{13} \mathrm{~N}\right]$ ammonia $\left(\left[{ }^{13} \mathrm{~N}\right] \mathrm{NH}_{3}\right)$, or any other tracer except $\left[{ }^{15} \mathrm{O}\right]$ water, suffer from partial volume effects due to the limited spatial resolution of PET, whereas $\left[{ }^{15} \mathrm{O}\right]$ water measurements do not. Furthermore, the PTF can be used to estimate the so-called perfusable tissue index (PTI) which has been shown to be a marker of tissue viability [23]. As such, perfusion and viability, distinguishing ischaemia from infarction, can be measured using a single scan. Tracer kinetic analysis of $\left[{ }^{15} \mathrm{O}\right]$ water used to be time-consuming, but recent years have seen the development of a number of software packages that nearly automatically supply MBF values based on dynamic scans, or are even capable of automated calculation of parametric images of MBF, PTF, and blood volume, and even left ventricle $(\mathrm{LV})$ volumes and ejection fraction $(\mathrm{EF})$ based on either first-pass gated images or gated parametric blood volume images $[16,17]$. The short half-life of $\left[{ }^{15} \mathrm{O}\right]$ water allows for the completion of a rest-stress protocol within $30 \mathrm{~min}$.

Dosimetry $\left[{ }^{15} \mathrm{O}\right]$ water: $1 \mathrm{mSv} / \mathrm{GBq}[24-26]$. A typical protocol consisting of two injections of $400 \mathrm{MBq}$ will result in an effective dose of $0.8 \mathrm{mSv}$.

Table 2 Comparison of the available tracers for quantitative perfusion PET

\begin{tabular}{|c|c|c|c|c|}
\hline & {$\left[{ }^{15} \mathrm{O}\right]$ water } & {$\left[{ }^{13} \mathrm{~N}\right] \mathrm{NH}_{3}$} & ${ }^{82} \mathrm{Rb}$ & {$\left[{ }^{18} \mathrm{~F}\right]$ flurpiridaz } \\
\hline Radionuclide half-life & $122 \mathrm{~s}$ & $9.96 \mathrm{~min}$ & $75 \mathrm{~s}$ & $109.8 \mathrm{~min}$ \\
\hline Availability & On-site cyclotron & On-site cyclotron & Generator & $\begin{array}{l}\text { Cyclotron (possible } \\
\text { shipping) }\end{array}$ \\
\hline $\begin{array}{l}\text { Mean positron range in } \\
\text { water }(\mathrm{mm})[20]\end{array}$ & 2.5 & 1.5 & 5.9 & 0.6 \\
\hline Relationship with $\mathrm{MBF}$ & Ideal (freely diffusible) & High extraction fraction & $\begin{array}{l}\text { Non-linear extraction } \\
\text { fraction }\end{array}$ & $\begin{array}{l}\text { High extraction } \\
\text { fraction }\end{array}$ \\
\hline Image quality & Parametric MBF images only & Good to high & Fair to good & Very high \\
\hline Gated imaging & Possible from first pass (blood pool) & High quality & Good quality & High quality \\
\hline Time schedule & Very tight & $\begin{array}{l}\text { Interval between rest and } \\
\text { stress injections }\end{array}$ & Very tight & $\begin{array}{l}\text { Separate stress and } \\
\text { rest injections }\end{array}$ \\
\hline Previous experience & $\begin{array}{l}\text { Used mainly in research setting and } \\
\text { with hybrid imaging }\end{array}$ & $\begin{array}{l}\text { Widely used qualitatively } \\
\text { and quantitatively }\end{array}$ & $\begin{array}{l}\text { Widely used qualitatively } \\
\text { and quantitatively }\end{array}$ & $\begin{array}{l}\text { Presently ongoing } \\
\text { phase III trial }\end{array}$ \\
\hline
\end{tabular}

$M B F=$ myocardial blood flow 
Fig. 2 Transport rate constant from plasma to tissue $\left(K_{1}\right)$ as function of $\mathrm{MBF}$ for $\left[{ }^{15} \mathrm{O}\right]$ water, $\left[{ }^{13} \mathrm{~N} \mathrm{NH}_{3}\right.$ [2] and ${ }^{82} \mathrm{Rb}[29]$ compared with the SPECT tracer $\left[{ }^{99 \mathrm{~m}} \mathrm{Tc}\right] \mathrm{Tc}$-sestamibi [30]. For $\left[{ }^{13} \mathrm{~N}_{\mathrm{NH}}\right.$, curves based on uptake rate $\left(K_{1}\right)$ and on retention, that is, the transport rate into the metabolically trapped compartment, are given

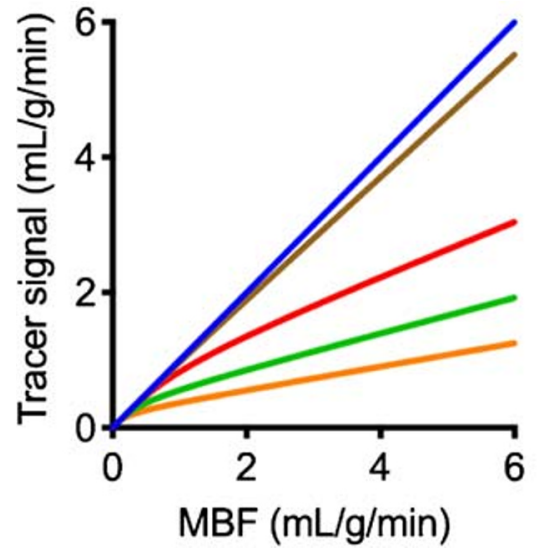

- ${ }^{15} \mathrm{O}$-water

$-{ }^{13} \mathrm{~N}$-ammonia uptake rate

$-{ }^{13} \mathrm{~N}$-ammonia retention

- ${ }^{82} \mathrm{Rb}$

- ${ }^{99 \mathrm{~m}} \mathrm{Tc}$-sestamibi
${ }^{82} \mathbf{R b}$

${ }^{82} \mathrm{Rb}$ has been employed as a myocardial perfusion agent since the early 1980s and has been extensively used for qualitative and quantitative cardiac PET [5, 27-29]. ${ }^{82} \mathrm{Rb}$ decays with a half-life of $75 \mathrm{~s}$ with emission of a positron with a maximal energy of $3.15 \mathrm{MeV}$ in $95.5 \%$ of decays or by electronic capture in $4.5 \%$ of decays with subsequent gamma emission. The high energy range of these positrons results in an intrinsic lower spatial resolution of PET images than with $\left[{ }^{13} \mathrm{~N}_{\mathrm{NH}}\right.$ or ${ }^{18} \mathrm{~F}$-radiolabelled tracers [20]. In particular, the resolution loss in soft tissues has been calculated to be greater than $2 \mathrm{~mm}$ [21]. ${ }^{82} \mathrm{Rb}$ has the same biological properties as potassium $\left(\mathrm{K}^{+}\right)$and is extracted by the myocardium through the Na-KATPase pump. ${ }^{82} \mathrm{Rb}$ is taken up in viable myocardium, whilst it is rapidly cleared from fibrotic tissue. The extraction of ${ }^{82} \mathrm{Rb}$ during the first pass is high $(65 \%)$ but decreases in a nonlinear way with increasing blood flow $[28,29]$. This effect is clear when compared with $\left[{ }^{13} \mathrm{~N}\right] \mathrm{NH}_{3}$ or $\left[{ }^{15} \mathrm{O}\right]$ water, although extraction is slightly better than for the most common ${ }^{99 \mathrm{~m}} \mathrm{Tc}$ labelled radiopharmaceuticals [30] (Fig. 2). ${ }^{82} \mathrm{Rb}$ can be eluted on demand from a Strontium- $82\left({ }^{82} \mathrm{Sr}\right) /{ }^{82} \mathrm{Rb}$ generator. In 1986, Gould et al. published the first clinical use of an ${ }^{82} \mathrm{Sr} /{ }^{82} \mathrm{Rb}$ generator for the detection of coronary artery disease (CAD) [31]. ${ }^{82} \mathrm{Rb}$ PET demonstrated higher diagnostic performance in comparison with single-photon emission computed tomography (SPECT) with ${ }^{201}$ Thallium $\left({ }^{201} \mathrm{Tl}\right)$, and this supported the approval by the Food and Drug Administration (FDA) of ${ }^{82} \mathrm{Sr} /{ }^{82} \mathrm{Rb}$ generators for clinical use in the USA [32]. The ${ }^{82} \mathrm{Sr} /{ }^{82} \mathrm{Rb}$ generators are commercially available in the USA and Canada and are currently in the process of approval for clinical use in Europe. The ${ }^{82} \mathrm{Sr} /{ }^{82} \mathrm{Rb}$ generator is positioned into a dedicated injection system that flushes saline through the generator. Volume and flow rate of saline can be manually selected and adapted to the 'age' of the generator.

${ }^{82} \mathrm{Rb}$ is eluted from the generator with a volume of saline between 10 and $50 \mathrm{~mL}$ and at a flow rate between $20 \mathrm{~mL} /$ min at the beginning of the life of the generator up to $35 \mathrm{~mL} /$ min at the end of the life of the generator because the concentration of ${ }^{82} \mathrm{Rb}$ decreases over time in the eluate. Recommended activities of ${ }^{82} \mathrm{Rb}$ to inject to patients are $10 \mathrm{MBq} / \mathrm{kg}$ (with a minimal dose of $740 \mathrm{MBq}$ and maximal dose of $1480 \mathrm{MBq}$ ) for PET acquisitions in a 3D mode. However, generators may need re-calibration when administered activity is changed, which makes weight-based dosing impractical in high-throughput centres. Furthermore, the high end of this interval may increase the risk of detector saturation. The use of fixed doses ranging from 740 to $1110 \mathrm{MBq}$, according to the PET/CT device sensitivity, is as well acceptable. As these injected activities should be doubled for PET acquisitions in 2D mode, we advocate the use of 3D mode acquisitions. One important concern regarding ${ }^{82} \mathrm{Sr} /{ }^{82} \mathrm{Rb}$ generators is the risk of ${ }^{82} \mathrm{Sr}$ and ${ }^{85} \mathrm{Sr}$ breakthrough. This risk increases with the 'age' of the generator and the total volume of eluate. The level of ${ }^{82} \mathrm{Sr}$ and ${ }^{85} \mathrm{Sr}$ in the eluate should be monitored daily. It can be estimated by measuring the residual activity in the eluate after complete decay of ${ }^{82} \mathrm{Rb}$. Newer ${ }^{82} \mathrm{Sr} /{ }^{82} \mathrm{Rb}$ generator and injection systems have the advantage of providing automated controls of residual ${ }^{82} \mathrm{Sr}$ and ${ }^{85} \mathrm{Sr}$ activities in the eluate. In addition, these systems are equipped with a second injector that is connected to the infusion system at the exit of the ${ }^{82} \mathrm{Sr} /{ }^{82} \mathrm{Rb}$ generator. This second injector allows for a constant administration rate of ${ }^{82} \mathrm{Rb}$ independent of the "age" of ${ }^{82} \mathrm{Sr} /{ }^{82} \mathrm{Rb}$ generator and the concentration of ${ }^{82} \mathrm{Rb}$ in the eluate. ${ }^{82} \mathrm{Rb}$ is well suited for clinical use of PET MPI. First of all, ${ }^{82} \mathrm{Rb}$ can be obtained on demand after elution of the ${ }^{82} \mathrm{Sr} /{ }^{82} \mathrm{Rb}$ generator. Second, the short half-life makes sequential rest and stress PET acquisition possible in $30 \mathrm{~min}$ without the presence of residual activity in the myocardium of the first ${ }^{82} \mathrm{Rb}$ injection. Finally, ${ }^{82} \mathrm{Rb}$ accumulates in the myocardium allowing for the evaluation of viability and myocardial contractility. The intrinsic limitations of ${ }^{82} \mathrm{Rb}$ are, however, the high energy of the emitted positron that worsens spatial resolution and thus the MPI quality, and the non-linear myocardial uptake at high blood flow that limits the precision of the quantification of hyperaemic/stress MBF. 
Dosimetry ${ }^{82} \mathrm{Rb}: 1.1 \mathrm{mSv} / \mathrm{GBq}[26,33]$. The effective dose depends on the exact protocol used, but two injections of $10 \mathrm{MBq} / \mathrm{kg}$ result in an effective dose of approximately $1.5 \mathrm{mSv}$.

\section{$\left[{ }^{13} \mathrm{~N}^{\mathrm{NHH}} \mathrm{H}_{3}\right.$}

$\left[{ }^{13} \mathrm{~N}\right] \mathrm{NH}_{3}$ has been employed as myocardial perfusion agent since the seventies of the last century [34]. It is produced by a cyclotron by means of the ${ }^{16} \mathrm{O}(\mathrm{p}, \alpha)^{13} \mathrm{~N}$ reaction. It has a relatively low positron energy $(1.19 \mathrm{MeV})$, with low-resolution loss (about $0.2 \mathrm{~mm}$ ) [20,21], and a 9.96-min half-life, which permit to acquire higher quality images than with the other commonly used tracers, although a rest-stress study requires a slightly longer acquisition time than with $\left[{ }^{15} \mathrm{O}\right]$ water and ${ }^{82} \mathrm{Rb}$ [35]. In blood, $\left[{ }^{13} \mathrm{~N} \mathrm{NH}_{3}\right.$ is mainly present as ammonium ion $\left(\mathrm{NH}_{4}{ }^{+}\right)$, which can cross the cell membrane through the sodium-potassium exchange system, whilst $\left[{ }^{13} \mathrm{~N}^{\mathrm{N}} \mathrm{NH}_{3}\right.$ diffuses passively because of its lipophilicity. Within the cell, $\left[{ }^{13} \mathrm{~N}\right] \mathrm{NH}_{3}$ may enter various metabolic pathways, among which the glutamic acid-glutamine is the most important, or back diffuse to blood [36]. Thus, the final myocardial uptake is influenced by several variables, including flow, extraction fraction and metabolic status. It has been demonstrated that $\left[{ }^{13} \mathrm{~N} \mathrm{NH}_{3}\right.$ extraction is inversely and non-linearly related to blood flow, with values ranging from 0.8 at baseline flow to 0.6 at flow about $3 \mathrm{~mL} / \mathrm{min} / \mathrm{g}$ [35]. On the other hand, the metabolic effects are probably small [36]. $\left[{ }^{13} \mathrm{~N}^{-} \mathrm{NH}_{3}\right.$ can be effectively used for the evaluation of relative myocardial uptake, and it has been demonstrated to be superior to SPECT MPI in terms of sensitivity and specificity [37]. ECG-gated PET studies are of high quality, but the stress acquisition is performed with some delay after tracer injection, although much closer as compared with gated SPECT, and then might not represent the truly functional status during stress. Finally, and most importantly, $\left[{ }^{13} \mathrm{~N}^{-N_{3}}\right.$ is highly valuable for the absolute quantitative measurement of $\mathrm{MBF}[2,4,38-40]$.

Dosimetry $\left[{ }^{13} \mathrm{~N}\right] \mathrm{NH}_{3}: 2 \mathrm{mSv} / \mathrm{GBq}[26,33]$. A typical protocol consisting of two injections of $400 \mathrm{MBq}$ will result in an effective dose lower than $1.8 \mathrm{mSv}$.

\section{PET acquisition protocols}

\section{Stress protocols}

Because the quantitative MBF measurement requires the acquisition of the input function, pharmacologic stress is the sole possible option. The stress test modalities do not differ for the various tracers and are the same as for SPECT MPI [41], although the execution of the stress injection with the patient already positioned on the camera bed, together with the additional problem to avoid his/her motion, requires particular cautiousness (Fig. 3). The commonly used stressors are dipyridamole, adenosine and, most recently, regadenoson. Dipyridamole, however, is not approved for this indication in many European countries and cannot be recommended anymore. The commonly used vasodilators can be contraindicated in case of severe chronic obstructive pulmonary disease, in particular with asthma components, and an alternative stress test could be dobutamine combined with atropine, although it is still debated whether this allows for reaching maximal hyperaemia [42, 43]. Patients must be fasting for at least $6 \mathrm{~h}$ and refrain from caffeinated beverages, food and analgesics containing caffeine for at least $12 \mathrm{~h}$ and from xanthine containing drugs for $48 \mathrm{~h}$. Dipyridamole/Persantin should be stopped $24 \mathrm{~h}$ prior to vasodilator infusion. Withdrawal of cardiac drugs can be considered according to the exam indications and the patient conditions. It is recommended to monitor arterial blood pressure and to record a 12-lead ECG during stress to identify ischaemic ECG changes and potential induced arrhythmias. It is advisable to thoroughly instruct patients on the necessity to remain relaxed and avoid movements even in case of symptoms. For all these circumstances, the use of regadenoson appears most advantageous in the setting of perfusion PET, both because of the more favourable symptom and adverse effect profile and because it significantly shortens and simplifies the stress protocol, reducing the degree of patient motion [44-46]. Moreover, similar values of stress MBF have been reported in the comparison with dipyridamole [47]. The best position is supine with the arms over the head. Because this position must be kept for a relatively prolonged time, all possible care must be given to make the patient comfortable and capable of remaining motionless without unduly effort. Arm rests or other supportive measures may be useful to this purpose.

\section{Acquisition protocols}

In the majority of systems, CT for attenuation correction is acquired before the PET acquisition. Patients must be instructed to breathe regularly during $\mathrm{CT}$ acquisition (see "Attenuation correction" section) and to avoid any movement during the bed translation under the PET detector. A respiration-averaged low-dose CT can be acquired, using essentially a respiratory gating protocol with all gates summed. This provides an attenuation map that is the closest match to the PET images and, in this regard, should be considered the first choice, if feasible. However, a respiration-averaged CT covering the whole breathing cycle can result in a quite high radiation dose, so a free breathing, relatively slow CT is a good second-best option. The radiation dose of performing a low-dose CT in a patient is $<1 \mathrm{mSv}$, down to $0.1 \mathrm{mSv}$ for an ultra-low-dose CT on a latest generation PET/CT scanner. The standard sequence for myocardial perfusion PET is rest- 
Fig. 3 Protocols for rest-stress quantitative cardiac PET. The upper panel shows the sequence for tracers with short half-life $\left(\left[{ }^{15} \mathrm{O}\right]\right.$ water, $\left.{ }^{82} \mathrm{Rb}\right)$. The lower panel shows the standard sequence for longer half-life tracers $\left(\left[{ }^{13} \mathrm{~N}\right] \mathrm{NH}_{3},\left[{ }^{18} \mathrm{~F}\right]\right.$ flurpiridaz); however, using correction for residual activity, the shorter protocol can be adopted also for $\left[{ }^{13} \mathrm{~N}_{\mathrm{NH}} \mathrm{N}_{3}\right.$

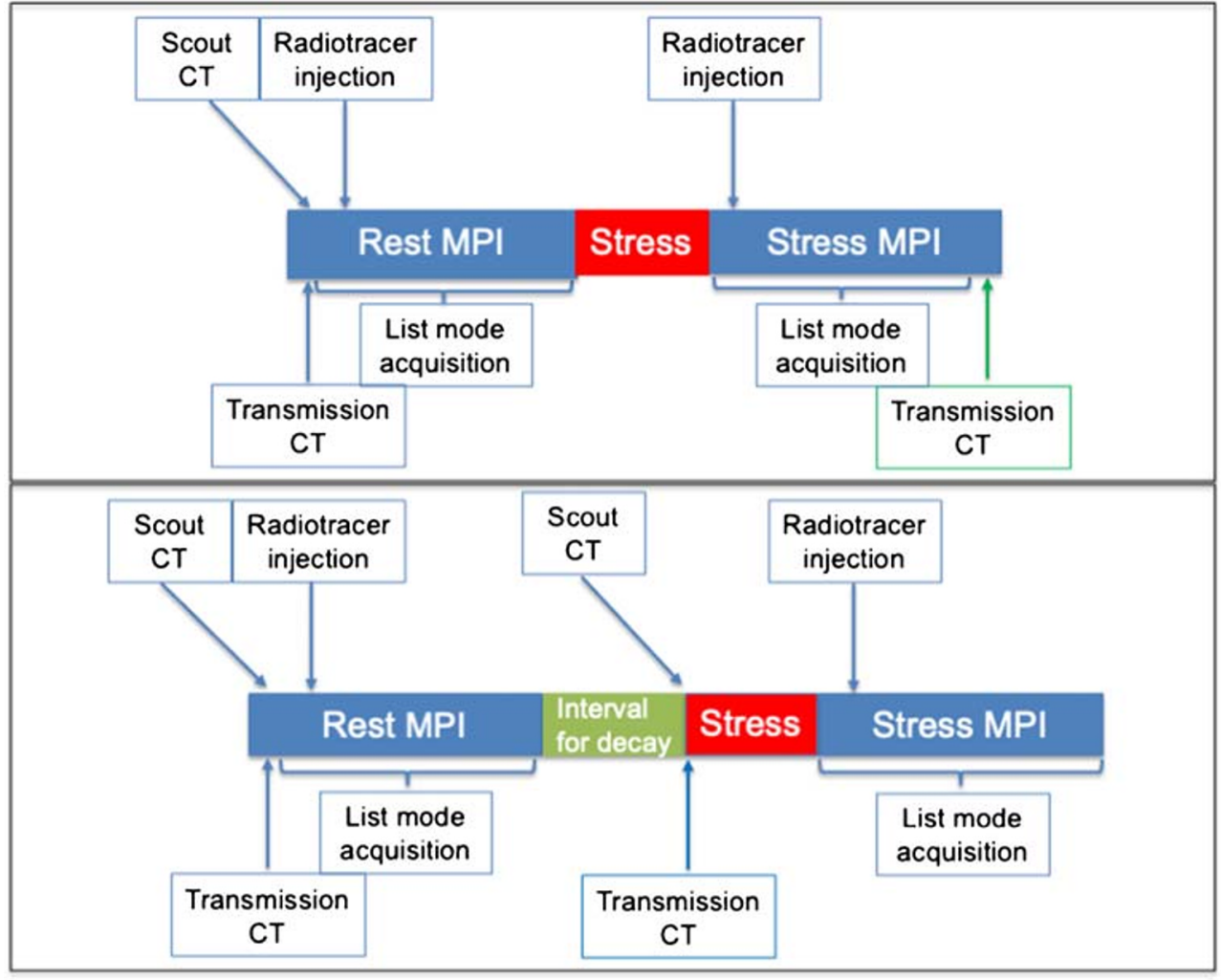

stress, since both studies are performed during the same session, and thus, the residual effects of the pharmaceutical stress agent on perfusion could affect the resting images. However, particularly using $\left[{ }^{15} \mathrm{O}\right]$ water in the setting of hybrid imaging including coronary CT angiography (CCTA), the acquisition of a sole stress study has been effectively performed (see "Hybrid imaging" section).

\section{$\left[{ }^{15}\right.$ O]water}

In contrast to tracers that stay confined to the myocardium, $\left[{ }^{15} \mathrm{O}\right]$ water is freely diffusible and acquisition protocols are focused in all cases on obtaining arterial input function and tissue response to quantify MBF in absolute terms. For stress acquisition, the tracer is administered after maximum vasodilation has been achieved. $\left[{ }^{15} \mathrm{O}\right]$ water is then injected as a bolus followed by a saline flush, in case of adenosine preferably over a second intravenous access not to interfere with its continuous flow rate. Preferably, administration should be done using a fast-controlled automated injection to ensure a constant bolus, for example injection $5 \mathrm{~mL}$ of $\left[{ }^{15} \mathrm{O}\right]$ water at $1 \mathrm{~mL} / \mathrm{s}$ followed by $35 \mathrm{~mL}$ saline at $2 \mathrm{~mL} / \mathrm{s}$ [25]. A dynamic frame sequence is initiated upon injection of $\left[{ }^{15} \mathrm{O}\right]$ water with a duration of $4 \mathrm{~min}$, which is sufficient since equilibrium between blood and tissue has been reached before that time point. It is essential to have a clear communication between the person on the infusion system and the technologist in the control room. Stress acquisition can be acquired as little as 10 min after the rest acquisition, given the short physical half-life of $\left[{ }^{15} \mathrm{O}\right]$ water. Due to the relative short biological half-life of adenosine, it is important that adenosine infusion is continued throughout the entire stress scan, which is another reason not to scan longer than $4 \mathrm{~min}$. Respirationaveraged low-dose CT for attenuation correction is ideally obtained separately for rest and for stress $\left[{ }^{15} \mathrm{O}\right]$ water acquisitions to account for the anatomical different position of the heart during stress as compared with rest (i.e. 'myocardial creep'). It has to be underscored that $\left[{ }^{15} \mathrm{O}\right]$ water modelling for quantification of perfusion is based on its clearance rate rather than uptake rate (see "Quantification of myocardial blood flow" section below). Since attenuation correction affects the amplitude of time-activity curves but does not further change the shape of these curves, an erroneous attenuation correction does not affect $\mathrm{MBF}$ values for $\left[{ }^{15} \mathrm{O}\right]$ water to a large extent (Fig. 4). Studies without attenuation correction have been conducted for $\left[{ }^{15} \mathrm{O}\right]$ water and have shown little impact on MBF values [25]. 


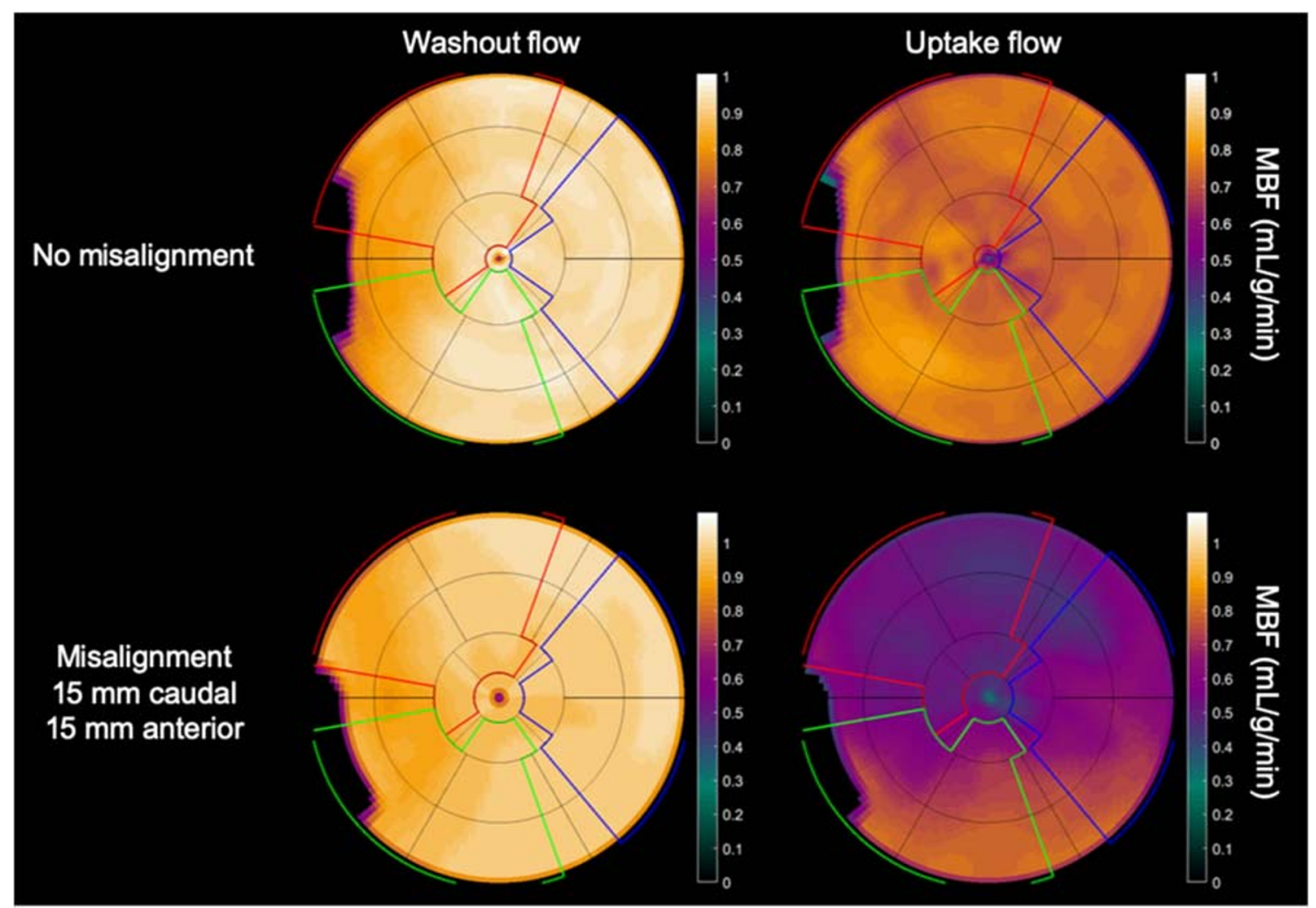

Fig. 4 Effect of $15 \mathrm{~mm}$ PET/CT misalignment on absolute MBF for values measured from washout rate $\left(\left[{ }^{15} \mathrm{O}\right]\right.$ water; left $)$ and values measured from uptake rate $\left({ }^{82} \mathrm{Rb}\right.$ or $\left[{ }^{13} \mathrm{~N}\right] \mathrm{NH}_{3}$; right). Polar maps are based on

${ }^{82} \mathrm{Rb}$

Acquisition usually starts with rest images to reduce the impact of residual effects of stress (myocardial stunning after ischaemia). As for $\left[{ }^{15} \mathrm{O}\right]$ water, low-dose $\mathrm{CT}$ acquisitions should be preferably obtained before the rest and after the stress for attenuation correction of PET images. Depending on the PET-CT system and patient position, it might be necessary to connect the infusion system of ${ }^{82} \mathrm{Rb}$ to the patient only after the acquisition of the CT in order to keep the length of the infusion system as short as possible. In addition, acquisition protocols that use the low-dose CT acquired after the stress for attenuation correction for both rest and stress PET acquisitions have been proposed to reduce the radiation exposure of patients, but possible problems related to the 'myocardial creep' should be considered. A minimal duration of $10 \mathrm{~min}$ is requested between rest and stress injections so that the generator is fully replenished. The same protocol is followed for both rest and stress PET acquisitions. PET data are acquired in list mode (to allow re-binning for gated and dynamic datasets for MBF calculations) for at least $5 \mathrm{~min}$. The PET acquisition should be ready to initiate on the system when the button to start the elution of the ${ }^{82} \mathrm{Sr} /{ }^{82} \mathrm{Rb}$ generators is pressed, and this should be clearly communicated. Then, the acquisition begins as soon as activity is detected on the PET detectors. the same simulated MBF scans for both cases. Misalignment results in a very slight increase in measured $\mathrm{MBF}$ for $\left[{ }^{15} \mathrm{O}\right]$ water and in a large anterior defect for ${ }^{82} \mathrm{Rb}$ or $\left[{ }^{13} \mathrm{~N}\right] \mathrm{NH}_{3}$

$\left[{ }^{13} \mathrm{~N}\right] \mathrm{NH}_{3}$

In case of $\left[{ }^{13} \mathrm{~N}\right] \mathrm{NH}_{3}$, at least 5 half-lives should be left between the two studies (i.e. $\approx 50 \mathrm{~min}$ ). To optimise the patient throughput it is reasonable to proceed with the acquisition of the resting study of at least another patient and then come back to the former one for the stress acquisition. Shortened protocols for $\left[{ }^{13} \mathrm{~N}_{\mathrm{NH}}\right.$ have been proposed, adjusting for residual activity of the resting injected dosage, but the effectiveness of the correction methods is not yet definitively established $[48,49]$. For $\left[{ }^{13} \mathrm{~N}\right] \mathrm{NH}_{3}$, PET acquisitions are the same for the rest and the stress studies. Since patients have to be repositioned on the examination bed for the stress study, a second CT for attenuation is usually required. Tracer injection is ideally performed using an automated injection system and image acquisition is started immediately or a few seconds before the start of tracer injection. Again, clear communication between the involved personnel is mandatory. The optimal acquisition protocol is in list mode for approximately $10 \mathrm{~min}$. The data will be subsequently re-binned to obtain the dynamic image sequence necessary for MBF measurement and gated images of the final tracer uptake for visual assessment and volume calculations. Alternatively, a list mode (or predefined frame mode) acquisition of about $10 \mathrm{~min}$ can be performed for 
quantitative MBF measurement, immediately followed by a single static rest and stress gated acquisition for another 5 to $10 \mathrm{~min}$.

\section{Image reconstruction}

\section{Recommendations common to all perfusion radiotracers}

The acquired data are corrected for geometry, randoms, scatter, normalisation and dead time losses. Specific problems may arise in older scanners when the high activities injected may cause overflow and dead time problems especially when using ${ }^{82} \mathrm{Rb}$. The general recommendation is to use a pixel size of 2-3 mm, but slightly larger dimensions can be employed without affecting quantitation. Iterative reconstruction methods are nowadays the standard in most scanners performing 3D imaging. In general, these algorithms improve both image quality and the signal to noise ratio as compared with the standard filtered back projection, but there are still uncertainties on the best possible methodology, which also depends on the particularities of the individual scanner [50]. Furthermore, it must be considered that changing the type of reconstruction algorithm could influence the final MBF measurement $[51,52]$.

\section{Attenuation correction}

In theory, older scanners with line-source-based attenuation correction are still valid for cardiac studies, because these transmission images are usually well comparable with the PET emission images. Indeed, the exact overlap between a high-resolution frozen image such as the CT acquired for attenuation correction and the blurred PET images, which are the sum of multiple heart cycles and breathing phases, remains a central problem for cardiac PET. Preferably, a respirationaveraged low-dose CT, using a protocol similar to that used for retrospective respiratory gating, should be used [53]. If this option is not feasible, a continuous shallow breathing (the same condition that the patient should be instructed to keep for the whole duration of the PET study, see above) is the preferred condition for achieving a CT image that can most effectively overlap with the PET image. However, images should always be checked for misalignment between PET and $\mathrm{CT}$, and misalignment should be corrected for prior to reconstruction (Fig. 5) [54]. Metal artefacts can present a challenge for the reconstruction algorithms and must be compensated for to produce accurate attenuation maps. Currently, several metal artefact reduction methods have been introduced in modern CT systems [55].

\section{Respiratory and patient motion correction}

The adverse influence of breathing and patient motion on cardiac images has been well demonstrated. Several approaches have been proposed for correcting the respiratory and patient motion artefacts using respiratory gating, including motion estimates in the reconstruction algorithm and even by limiting the respiratory motion with an abdominal belt [56-58]. So far, however, none of these quite complex methods has been widely applied.

\section{Dynamic images}

The frame duration during the first pass of the radioactivity through the heart is usually no less than $5 \mathrm{~s}$. After this, frame duration can be increased incrementally. Table 3 summarises some employed re-binning schemes for the various radiotracers. The sequence of the dynamic images on which the measurement of MBF will be performed must be checked for possible movement artefacts. Especially important is inter-frame motion, which is difficult to correct, but can heavily affect the accuracy of quantitative measurements, particularly during the rapid image sequence needed to obtain the time activity curves of the input function and of the initial tracer uptake. Even relatively limited breathing or patient movement can affect the position of the LV and of the myocardial wall. Some processing software packages have the capability to perform a motion correction. If this is not possible, the deletion of single frames could be considered.

\section{Recommendations specific to each radiotracer}

\section{$\left[{ }^{15}\right.$ O]water}

For $\left[{ }^{15} \mathrm{O}\right]$ water, no static images are available, but gating can be performed, and volumes and EF can be determined using first-pass blood volume images $[16,17]$. For this, data has to be acquired in list mode so both dynamic (whole scan) and gated (circa 10-50 s post injection, depending on injection speed) images can be reconstructed. Visual interpretable images can be generated using digital subtraction techniques of blood volume from tissue as well as automated parametric images of MBF at the voxel level, but calculation of 3D perfusion images is preferred, and software packages capable of doing this are now becoming commercially available, whilst others can be obtained at no costs from academic centres that developed them. They now routinely generate $3 \mathrm{D}$ perfusion images (Fig. 6) as well as regional MBF and regional myocardial flow reserve (MFR, i.e. the ratio of stress and rest $\mathrm{MBF}$ ) in absolute terms according to the standard 17segment model of the AHA [66]. Although validated in large-scale clinical studies, there is currently no FDA approval 
a

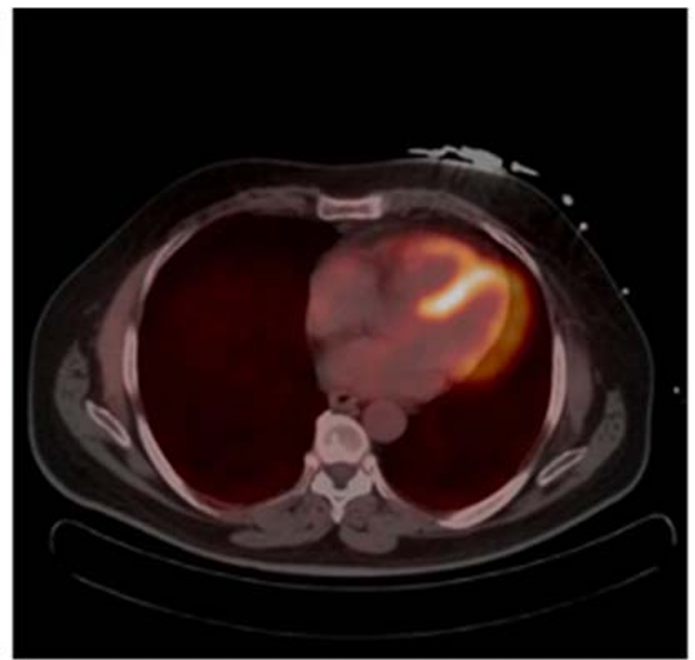

c

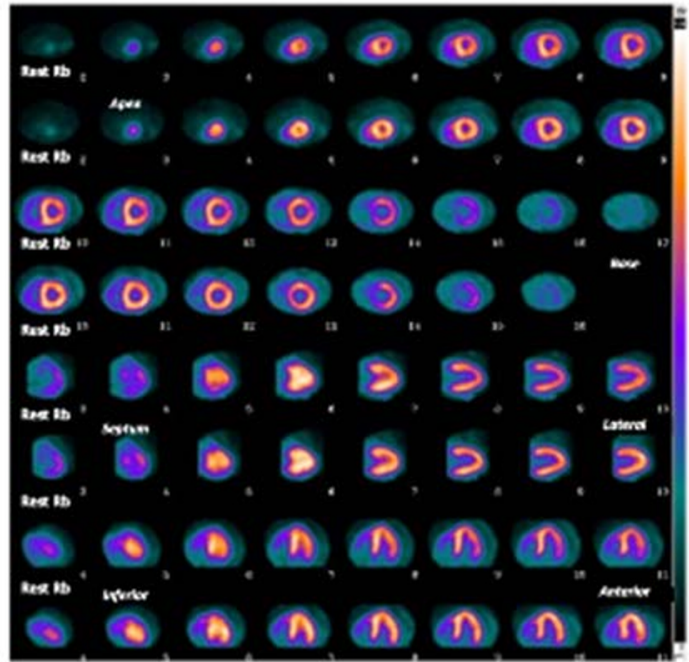

Fig. 5 Transmission-emission misalignment example. Misalignment between $\mathrm{CT}$ transmission and rest ${ }^{82} \mathrm{Rb}$ perfusion PET images (a) with correction of transmission-emission misalignment (b). Anterolateral perfusion defect on rest ${ }^{82} \mathrm{Rb}$ perfusion images (c, upper rows) deriving from

for $\left[{ }^{15} \mathrm{O}\right]$ water use in medical practice, but its use is approved in many European countries.

${ }^{82} \mathrm{Rb}$

At the end of the acquisition, the position of the heart on PET and $\mathrm{CT}$ acquisitions is visually matched for attenuation correction using dedicated software. From list mode acquisitions, three different PET reconstructed datasets can be obtained for both rest and stress studies: static (non-gated) acquisitions are reconstructed with PET data acquired between 90-120 s and 5-8 min after the injection, once the blood signal is low; gated acquisitions, which are reconstructed from PET data acquired within the same time interval post injection, usually divided in 8 (the best choice to contain noise) or 16 bins (better curve); and dynamic PET acquisitions. Several time frame schemes have been proposed for dynamic PET acquisition (Table 3). In b

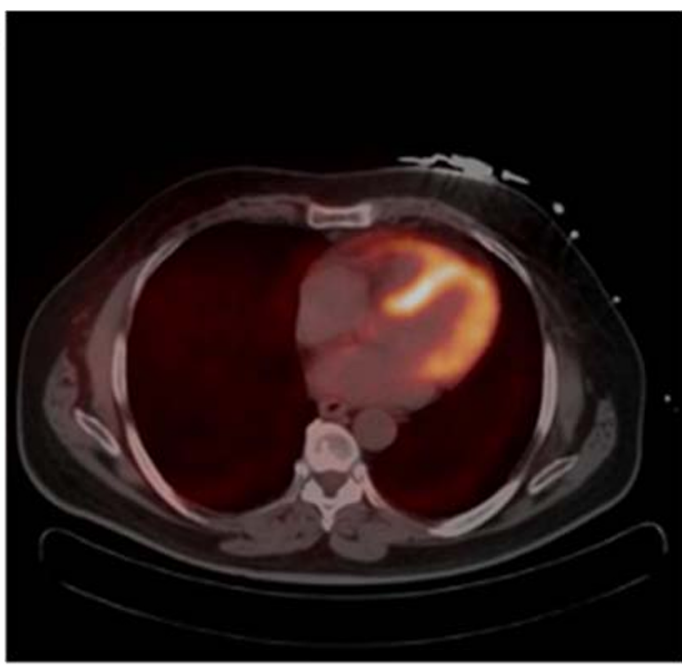

d

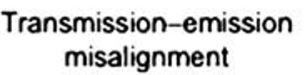

Transmission-emission corrected alignment

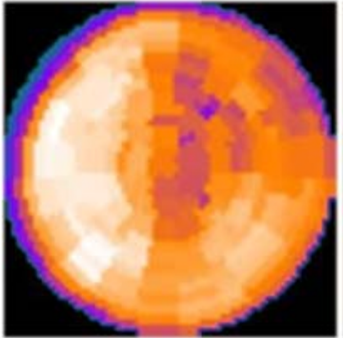

Summed Rest Score 11

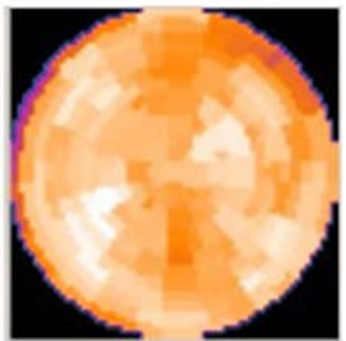

Summed Rest Score 0 applying the incorrect attenuation coefficients during tomographic reconstruction to an area of LV myocardium overlying lung field on CT transmission scan, and normal rest perfusion study (c, lower rows) after correction, with relative polar maps (d)

patients with LVEF $<30 \%$, the reconstruction of static and gated acquisitions should be started only $150-180 \mathrm{~s}$ after the injection to reduce the level of residual blood signal and improve the contrast between the myocardium and the LV cavity.

\section{$\left[{ }^{13} \mathrm{~N}_{\mathrm{NH}}\right.$}

List mode acquisition is the current preferred modality for $\left[{ }^{13} \mathrm{~N}\right] \mathrm{NH}_{3}$. Dynamic imaging for absolute quantification is currently performed with the re-binning into frames of increasing duration, starting with shorter frames for the input function and tracer uptake phases (first 2-3 min) and then with $30 \mathrm{~s}$ or 1-min frames (Table 3 ). Static images constructed with the data after tracer extraction are available for visual assessment and are usually obtained together with cardiac gating. The alternatives for gating are 8 bins or 16 bins (see above). 
Table 3 Examples of framing schemes for re-binning of dynamic list mode acquisitions

\begin{tabular}{|c|c|c|c|}
\hline Reference & Tracer & Frame sequence & Total time \\
\hline Kajander S et al. [59] & {$\left[{ }^{15} \mathrm{O}\right]$ water } & $14 \times 5 \mathrm{~s} ; 3 \times 10 \mathrm{~s} ; 3 \times 20 \mathrm{~s} ; 4 \times 30 \mathrm{~s}$ & $4 \min 40 \mathrm{~s}$ \\
\hline Danad I et al. [60] & {$\left[{ }^{15} \mathrm{O}\right]$ water } & $1 \times 10 \mathrm{~s} ; 8 \times 5 \mathrm{~s} ; 4 \times 10 \mathrm{~s} ; 2 \times 15 \mathrm{~s} ; 3 \times 20 \mathrm{~s} ; 2 \times 30 \mathrm{~s} ; 2 \times 60 \mathrm{~s}$ & $6 \min$ \\
\hline Clinical protocol in Aarhus, Amsterdam, Uppsala & {$\left[{ }^{15} \mathrm{O}\right]$ water } & $1 \times 10 \mathrm{~s} ; 8 \times 5 \mathrm{~s} ; 4 \times 10 \mathrm{~s} ; 2 \times 15 \mathrm{~s} ; 3 \times 20 \mathrm{~s} ; 2 \times 30 \mathrm{~s}$ & $4 \min$ \\
\hline Muzik O et al. [38] & {$\left[{ }^{13} \mathrm{~N}\right] \mathrm{NH}_{3}$} & $12 \times 10 \mathrm{~s} ; 4 \times 15 \mathrm{~s} ; 4 \times 30 \mathrm{~s} ; 3 \times 300 \mathrm{~s}$ & $20 \mathrm{~min}$ \\
\hline Hutchins GD et al. [40] & {$\left[{ }^{13} \mathrm{~N}\right] \mathrm{NH}_{3}$} & $12 \times 10 \mathrm{~s} ; 4 \times 30 \mathrm{~s} ; 1 \times 360 \mathrm{~s}$ & $10 \mathrm{~min}$ \\
\hline DeGrado TR et al. [39] & {$\left[{ }^{13} \mathrm{~N}\right] \mathrm{NH}_{3}$} & $12 \times 10 \mathrm{~s} ; 4 \times 30 \mathrm{~s} ; 3 \times 120 \mathrm{~s} ; 2 \times 300 \mathrm{~s}$ & $20 \mathrm{~min}$ \\
\hline Sciagrà R et al. [61] & {$\left[{ }^{13} \mathrm{~N}\right] \mathrm{NH}_{3}$} & $24 \times 5 \mathrm{~s} ; 2 \times 30 \mathrm{~s} ; 1 \times 60 ; 1 \times 300 \mathrm{~s}$ & $9 \min$ \\
\hline El Fahkri et al. [62] & ${ }^{82} \mathrm{Rb}$ & $24 \times 5 \mathrm{~s} ; 86 \times 30 \mathrm{~s}$ & $6 \min$ \\
\hline Lortie et al. [63] & ${ }^{82} \mathrm{Rb}$ & $12 \times 10 \mathrm{~s} ; 2 \times 30 \mathrm{~s} ; 1 \times 60 \mathrm{~s} ; 1 \times 120 \mathrm{~s}, 1 \times 240 \mathrm{~s}$ & $10 \mathrm{~min}$ \\
\hline Dekemp RA et al. [64] & ${ }^{82} \mathrm{Rb}$ & $9 \times 10 \mathrm{~s} ; 3 \times 30 \mathrm{~s} ; 1 \times 60 \mathrm{~s} ; 1 \times 120 \mathrm{~s}$ & $6 \min$ \\
\hline Dekemp RA et al. [64] & ${ }^{82} \mathrm{Rb}$ & $12 \times 10 \mathrm{~s} ; 2 \times 30 \mathrm{~s} ; 1 \times 60 \mathrm{~s} ; 1 \times 120 \mathrm{~s}$ & $6 \mathrm{~min}$ \\
\hline Dekemp RA et al. [64] & ${ }^{82} \mathrm{Rb}$ & $12 \times 5 \mathrm{~s} ; 6 \times 10 \mathrm{~s} ; 4 \times 20 \mathrm{~s} ; 4 \times 40 \mathrm{~s}$ & $6 \mathrm{~min}$ \\
\hline Armstrong IS et al. [52] & ${ }^{82} \mathrm{Rb}$ & $1 \times 10 \mathrm{~s} ; 8 \times 5 \mathrm{~s} ; 3 \times 10 \mathrm{~s} ; 2 \times 20 \mathrm{~s} ; 4 \times 60 \mathrm{~s}$ & $6 \min$ \\
\hline Gaudieri V et al. [65] & ${ }^{82} \mathrm{Rb}$ & $12 \times 5 \mathrm{~s} ; 6 \times 10 \mathrm{~s} ; 4 \times 20 \mathrm{~s} ; 4 \times 40 \mathrm{~s}$ & $6 \mathrm{~min}$ \\
\hline
\end{tabular}

\section{Interpretation of myocardial perfusion PET}

\section{Perfusion images}

\section{Perfusion images using extracted radiotracers $\left({ }^{82} \mathrm{Rb}\right.$ and $\left[{ }^{13} \mathrm{~N}\right]$} $\mathrm{NH}_{3}$ )

After attenuation correction and reconstruction, the myocardial images must be reoriented along the myocardial axis as usually performed for myocardial perfusion imaging. Currently, most vendors already offer cardiac processing software on their devices, mainly the same as used for SPECT MPI. In case of physiologically retained tracers that allow visualising the relative perfusion images, it is important to proceed with the analysis of the reoriented slices and check for the image quality. The normalisation and side-by-side display of the three reoriented slice sets (short axis, vertical and horizontal long axis) is performed as usual. Even in the setting of quantitative myocardial PET, it is necessary to perform (and to report) the analysis of the myocardial uptake in qualitative terms. Presently, most processing software packages also provide polar map displays of myocardial uptake and permit the comparison of the individual patient results with a reference database (or allow the user to create an own normal data base). It is therefore possible, and in case recommended, to integrate the quantitative measurement of $\mathrm{MBF}$ with the

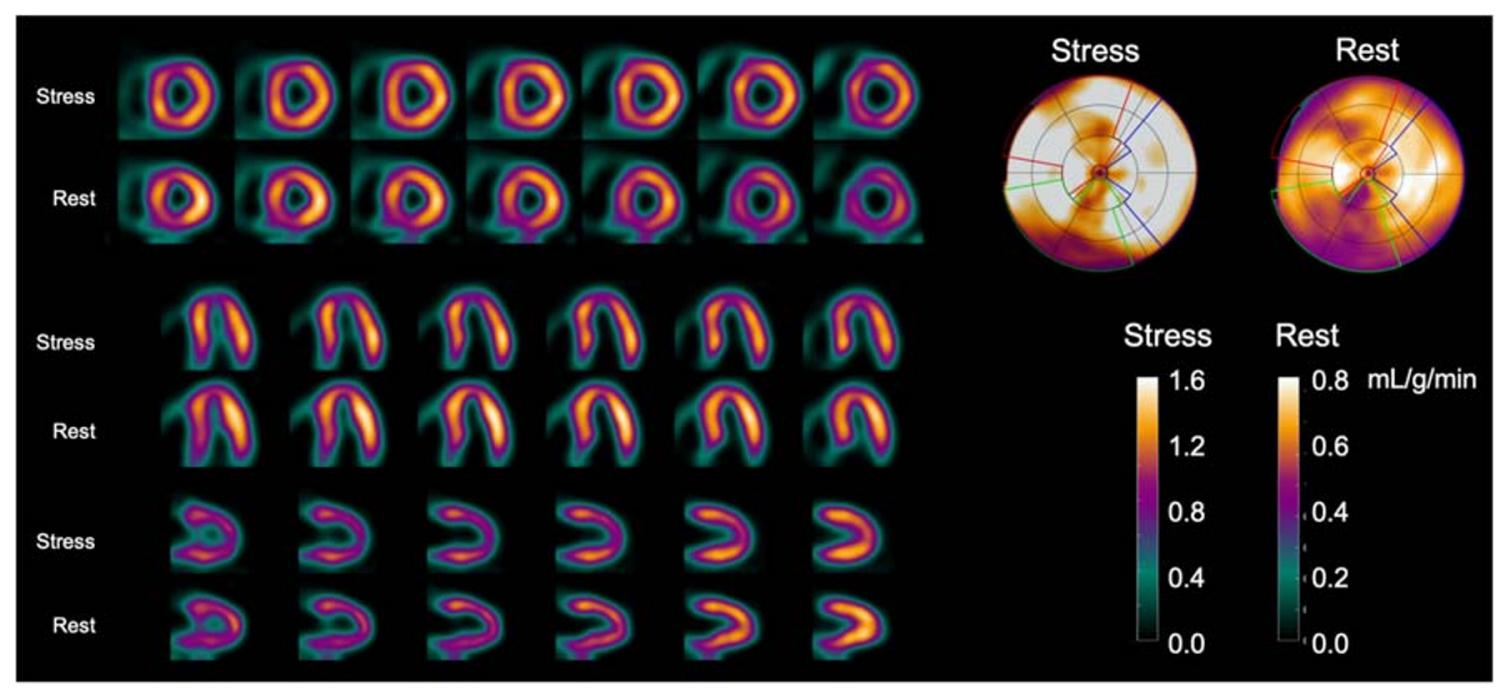

Fig. $6\left[{ }^{15} \mathrm{O}\right]$ water parametric MBF images from a 65 -year-old female with angina referred for assessment of ischaemia with PET. The images shown here are parametric MBF images based on 4-min dynamic $\left[{ }^{15} \mathrm{O}\right]$ water PET scans, with their corresponding polar maps. Note that colour scales of all images represent $\mathrm{MBF}$ in $\mathrm{mL} / \mathrm{g} / \mathrm{min}$ as seen in the colour bars. SPECT was negative. PET clearly shows balanced ischaemia with stress MBF far below the threshold of $2.3 \mathrm{~mL} / \mathrm{g} / \mathrm{min}$ 
assessment of the relative tracer distribution and with the comparison with a normal reference. Visual semi-quantitative image analysis is performed on a regional basis, using 17 segments (AHA model), and each segment is scored using a 5point scale ranging from 0 (normal perfusion), 1 (mildly reduced perfusion), 2 (moderately reduced perfusion), 3 (severely reduced perfusion), to 4 (absent perfusion). This yields a summed perfusion score for both stress and rest myocardial perfusion images. The reported cut-off values to discriminate abnormal from normal PET MPI are diverse. The most widely accepted threshold is to consider a summed stress score (SSS) $\geq 4$ as abnormal [67]. However, more restrictive thresholds have been proposed as well. For instance, Hsiao et al. classified an SSS $>0$ as abnormal [68]. Similarly, Dorbala et al. proposed to transform the scores in percentage and then to consider an $\mathrm{SSS} \%>1 \%$ as abnormal [69].

\section{Gated studies}

Most programs simultaneously reorient and analyse both the gated images and a summed static image. The same programs that are employed for SPECT MPI usually process the gated PET studies as well. Accordingly, LV volumes and LVEF can be derived and synchrony assessments can be determined. The visual display of the gated studies using a cine loop function permits to evaluate the regional LV wall motion. End-diastolic and end-systolic perfusion polar maps, together with motion and thickening polar maps, can be obtained. Since, as above mentioned, the programs that perform the assessment of LV function in gated PET do not differ from those already extensively used and verified for gated SPECT, no separate normality values have been established. However, dissimilarities among the various software packages have been reported and should be considered in case of comparison between studies performed in different centres [70]. For $\left[{ }^{13} \mathrm{~N} \mathrm{NH}_{3}\right.$, there are relatively few data in large populations to support the reliability of gated PET for clinical purposes, but there are no reasons to hypothesise a different behaviour as compared with ${ }^{82} \mathrm{Rb}$-gated PET. Moreover, good agreement between $\left[{ }^{13} \mathrm{~N}\right] \mathrm{NH}_{3}$ and magnetic resonance imaging (MRI) for the assessment of LVEF, volumes and wall motion has been reported [71]. The side-by-side display of rest and stress gated images is useful to identify changes in LV wall motion and global function. With regard to the assessment of LVEF reserve (i.e. change in LVEF from rest to stress), it has been demonstrated that a LVEF reserve $>+5 \%$ units has a very high negative predictive value for ruling out severe $\mathrm{CAD}$, and conversely, a reserve $<-5 \%$ units has a very high positive predictive value for severe CAD [72]. Other reports confirm that a LVEF reserve $<0$ is most probably related to abnormal perfusion and more severe CAD [67, 68]. It must be remembered that in the $\left[{ }^{13} \mathrm{~N}^{-} \mathrm{NH}_{3}\right.$ protocol, there is a slightly longer delay between stress and gated PET acquisition than when
${ }^{82} \mathrm{Rb}$ is used. Thus, with $\left[{ }^{13} \mathrm{~N}\right] \mathrm{NH}_{3}$, it would be more correct to define the stress acquisition as an early post-stress one. On the other hand, the time interval is still far shorter than in gated SPECT, and there are data suggesting that indeed even with $\left[{ }^{13} \mathrm{~N}\right] \mathrm{NH}_{3}$, stress-induced changes on LV function can be identified [61, 73, 74].

\section{Recommendations specific for $\left[{ }^{15} \mathrm{O}\right]$ water}

As already reported, $\left[{ }^{15} \mathrm{O}\right]$ water perfusion PET provides routine quantification and studies have shown that grading of flow values outperforms the diagnostic accuracy of visual defect grading. It is, therefore, uncommon to express $\left[{ }^{15} \mathrm{O}\right]$ water PET in traditional terms of SSS, summed rest score (SRS) and summed difference score (SDS). The parametric images are used to identify visually the ischaemic area and its extent, whereby validated thresholds of absolute hyperaemic MBF and MFR are used to distinguish normal from abnormal perfusion. The most employed approach is based on the threshold formerly identified using receiveroperator characteristic analysis and recently validated in the PACIFIC study and classifies as abnormal the finding of at least two adjacent myocardial segments with hyperaemic flow of $2.30 \mathrm{~mL} / \mathrm{min} / \mathrm{g}$ or less $[75,76]$. A similar method had been effectively used in the quantitative PET sub-study of the EVINCI trial [77]. The standard evaluation of gated PET based on uptake images cannot be performed with $\left[{ }^{15} \mathrm{O}\right]$ water, but LVEF can be determined using gated firstpass blood volume images covering the first minute after injection or gated parametric blood volume images $[16,17]$.

\section{Quantification of myocardial blood flow}

\section{General principles}

Compartment models can describe the kinetics of PET tracers for MBF. Figure 7, for example, shows a single-tissue compartment model, with rate constants $K_{1}$, describing the transport rate in $\mathrm{mL}$ per $\mathrm{g}$ tissue per min from blood to tissue, and $k_{2}$, which is the clearance rate from tissue per minute.

This simple compartment model can describe the kinetics of both $\left[{ }^{15} \mathrm{O}\right]$ water and ${ }^{82} \mathrm{Rb}$ during the first minutes after injection. To accurately describe the kinetics of $\left[{ }^{13} \mathrm{~N}^{-N_{3}}\right.$, a second irreversible compartment should be added, with a rate constant $k_{3}$ describing diffusion into the glutamine pool (Fig. 7). However, it has been proposed to disregard this compartment by limiting the analysis to the first $4 \mathrm{~min}$ and, thus, before that metabolic process begins [39]. For $\left[{ }^{15} \mathrm{O}\right]$ water, $K_{1}$ is identical to MBF, and $k_{2}$ is also proportional to $\mathrm{MBF}$ since water is freely diffusible and water that enters the tissue must be compensated by a similar amount clearing from the tissue to ensure mass balance. For ${ }^{82} \mathrm{Rb}$ and $\left[{ }^{13} \mathrm{~N} \mathrm{NH}_{3}\right.$, the relationship between $K_{1}$ and $\mathrm{MBF}$ can be described by the 


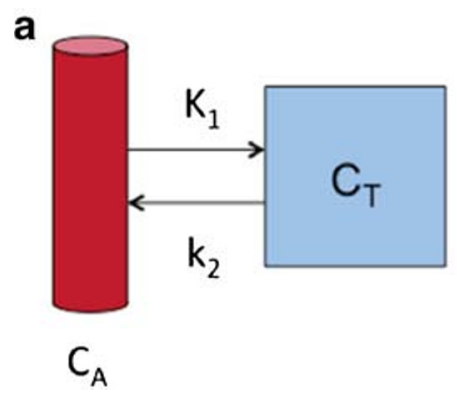

Fig. 7 Compartment models: a single-tissue compartment model; $\mathbf{b}$ irreversible two-tissue compartment model. $C_{\mathrm{A}}$ is the radioactivity concentration in arterial blood, $C_{\mathrm{T}}$ the radioactivity concentration in tissue, with

non-linear curves shown in Fig. 2, which have been established by comparison to either $\left[{ }^{15} \mathrm{O}\right]$ water or to animal studies with microspheres.

The equation describing the compartment model in Fig. 7a is as follows:

$$
C_{\mathrm{T}}(t)=K_{1} C_{\mathrm{A}}(t) \otimes e^{-k_{2} t}
$$

Here, $C_{\mathrm{A}}(t)$ is the radioactivity concentration in arterial blood over time during the scan, and $C_{\mathrm{T}}(t)$ is the radioactivity concentration in tissue over time. Since the radioactivity concentration measured within a volume of interest (VOI) or voxel in the myocardial wall also contains radioactivity in blood, as well as spill-over from the left- and right-ventricular (RV) cavities due to cardiac motion and the limited spatial resolution of PET, the total PET signal $C_{\mathrm{PET}}(t)$ can be described as follows:

$$
\begin{aligned}
C_{\mathrm{PET}}(t)= & \left(1-V_{\mathrm{LV}}-V_{\mathrm{RV}}\right) K_{1} C_{\mathrm{A}}(t) \otimes e^{-k_{2} t}+V_{\mathrm{LV}} C_{\mathrm{A}}(t) \\
& +V_{\mathrm{RV}} C_{\mathrm{RV}}(t)
\end{aligned}
$$

where $V=$ volume fraction. By fitting Eq. (2) to the measured time-activity curve in a volume or voxel, $K_{1}, k_{2}, V_{\mathrm{LV}}$ and $V_{\mathrm{RV}}$ can be estimated. Observe that the term before $K_{1}$ in principle should be one minus the fractional blood volume, but since fractional blood volume and LV spill-over cannot be estimated separately, $V_{\mathrm{LV}}$, which is the sum of both, has to be used. This term is sometimes omitted.

\section{$\left[{ }^{15}\right.$ O]water}

The single compartment model to utilise $\left[{ }^{15} \mathrm{O}\right]$ water PET for quantification of perfusion has been validated over decades ago and remains the reference standard owing to the kinetic properties of this tracer that meet virtually all the criteria as a perfect flow tracer. The model incorporates partial volume correction as well as RV and LV blood pool spill-over effects. In the special case of $\left[{ }^{15} \mathrm{O}\right]$ water, $k_{2}$ equals $\mathrm{MBF} / V_{\mathrm{T}}$, where $V_{\mathrm{T}}$ is the partition coefficient of water in tissue, established to be $0.91 \mathrm{~g} / \mathrm{cm}^{3}$ in myocardial tissue. In that case, MBF appears

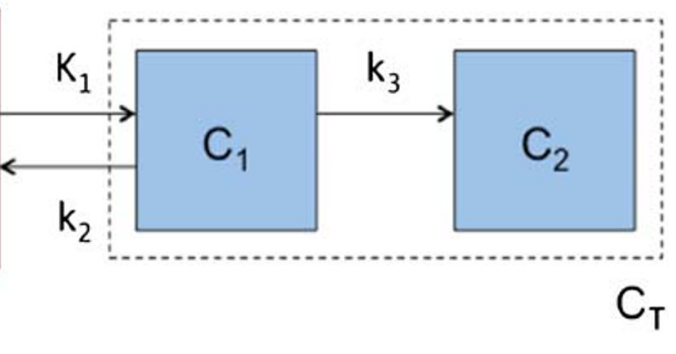

$C_{1}$ and $C_{2}$ describing free and internalised tracer in tissue, and $K_{1}, k_{2}$ and $k_{3}$ are rate constants describing the transport rates of tracer between the different compartments

twice in Eq. (1), since $K_{1}$ equals MBF. Hence, for $\left[{ }^{15} \mathrm{O}\right]$ water, Eq. (2) is generally re-written as:

$$
\begin{aligned}
C_{\mathrm{PET}}(t)= & \mathrm{PTF} \times \mathrm{MBF} \times C_{\mathrm{A}}(t) \otimes e^{-\frac{\mathrm{MBF}}{0.91} t}+V_{\mathrm{LV}} C_{\mathrm{A}}(t) \\
& +V_{\mathrm{RV}} C_{\mathrm{RV}}(t)
\end{aligned}
$$

The PTF accounts for both underestimation of radioactivity concentrations due to spill-out effects, but also to overestimation due to spill-in, providing an intrinsic correction for partial volume effects which is exclusive to $\left[{ }^{15} \mathrm{O}\right]$ water. In addition, it can be seen as a measure for discrepancies between the influx and clearance rate of $\left[{ }^{15} \mathrm{O}\right]$ water caused by non-perfusable tissue, such as scar tissue, within the VOI or voxel. Thus, for $\left[{ }^{15} \mathrm{O}\right]$ water, $\mathrm{MBF}$ is measured only in perfusable tissue, in contrast to other PET tracers, which measure transmural MBF. Transmural MBF can then be computed indirectly as MBF $\times$ $\mathrm{PTF} /\left(1+V_{\mathrm{LV}}+V_{\mathrm{RV}}\right)$. A basis function implementation of Eq. (3) allows for fast calculation of MBF values at the voxel level, resulting in parametric images of MBF [78]. Dividing PTF with the anatomical tissue fraction (ATF) allows for calculation of the PTI, a marker of myocardial tissue viability [22, 23]. When the PTI concept was first introduced, ATF was estimated by subtracting a normalised blood volume image based on an additional $\mathrm{C}^{15} \mathrm{O}$ scan from a PET attenuation image [23], but using a modern PET/CT scanner, the blood volume image can instead be obtained from $V_{\mathrm{LV}}$ and $V_{\mathrm{RV}}$ in Eq. (3), and hence, using $\left[{ }^{15} \mathrm{O}\right]$ water, both MBF and viability can now be measured using a single scan [79]. Although so far mainly used in selected research centres, $\left[{ }^{15} \mathrm{O}\right]$ water has been quite extensively applied in the clinical setting, and reference values for identifying MBF and MFR abnormalities have been reported. In particular, the demonstrated effectiveness of the hyperaemic MBF for characterising CAD patients has been advantageous in the setting of hybrid imaging and of stress only quantitative PET. There are limited data about the comparison of $\left[{ }^{15} \mathrm{O}\right]$ water results achieved using different platforms. In the single available study, two non-commercial platforms gave tightly comparable results, with no significant differences at rest, and small variance under stress, but with a very good interclass correlation coefficient [80]. 
${ }^{82} \mathrm{Rb}$

The use of ${ }^{82} \mathrm{Rb}$ made the wide application of PET for MPI possible. However, already at the beginning of the 1990s, the advantages of performing quantitative PET were acknowledged. In particular, the group of Gould et al. developed a simplified approach to MBF quantitation, referred as the retention model, based on the acquisition of a 2-min image after tracer injection [81]. Although based on several assumptions, this method was effective in deriving useful MBF and MFR estimates, which could be integrated in the more comprehensive concept of coronary flow capacity [82]. More recently, compartmental models have been developed and validated $[62,63,83]$. Because of the wide use of this tracer, particular emphasis has been given to the reproducibility of the calculated values. With regard to this point, the one-tissue compartment model proposed by Lortie et al. has been demonstrated to be the most reproducible, even if implemented in different software platforms $[64,84-86]$. However, there are differences in the measured values in normal subjects, which justify some caution in the comparison of data obtained using different platforms [87]. The approach used for defining the input function can affect the result agreement between different methods [88]. Using the prognostic implications as reference, MFR seems more consistent than hyperaemic MBF [88].

\section{$\left[{ }^{13} \mathrm{~N}^{\mathrm{N}} \mathrm{N}_{3}\right.$}

The approaches of MBF quantitation using $\left[{ }^{13} \mathrm{~N}^{-N_{3}}\right.$ are mainly based on compartmental models, although simplified approaches based on tracer retention have been used as well. In the retention approach, the signal in the myocardial wall is related to the net retention rate $K_{i}$ multiplied by the integral of the plasma activity over time $[2,4]$.

$C_{\mathrm{PET}}(t)=K_{i} \int_{0}^{t} C_{\mathrm{A}}(\tau) \mathrm{d} \tau$

Although $K_{i}$ underestimates MBF more than $K_{1}$ does, it is still proportional to MBF as seen in the red curve in Fig. 2. The proposed compartment models are the two-compartment model, similar to the already mentioned one-tissue compartment model, and the three-compartment model, which takes into account the metabolism of $\left[{ }^{13} \mathrm{~N}^{-N_{3}} \mathrm{H}_{3}\right.$ after myocardial uptake (Fig. 7b) [4, 38, 40, 89, 90]. The latter model has been also simplified by limiting the analysis to the first 4 min after tracer injection and accordingly neglecting the metabolic fate of $\left[{ }^{13} \mathrm{~N} \mathrm{NH}_{3}\right.$ [39]. The results achieved by these different compartmental models have been regarded as to be closely related to each other, but nevertheless show significant differences [91]. The analysis has been more recently expanded to the combination of the compartmental model and software platforms, showing, together with the good general agreement between the measures, the presence of inter-modality variations in $\mathrm{MBF}$, which are also partly influenced by patient characteristics $[92,93]$.

\section{Pitfalls and artefacts}

\section{General considerations}

A first and, unfortunately, unavoidable problem of quantitative PET is the impossibility to perform a physiological stress such as dynamic exercise to explore the MFR. As already mentioned above, this limitation is related to the need to obtain dynamic images during tracer injection and cannot be avoided even if perfusion tracers with longer half-life such as $\left[{ }^{18} \mathrm{~F}\right]$ flurpiridaz will become clinically available. Whether a simplified approach based on the $\left[{ }^{18} \mathrm{~F}\right]$ flurpiridaz standardised uptake values only will be effective for MFR assessment remains uncertain [94]. In addition, the need to place the patient in a supine position during acquisition is another potential problem of quantitative PET.

The problem of achieving a correct alignment between PET and CT images for attenuation correction is common to all types of cardiac PET investigation but can be particularly challenging in case of quantitative studies [95]. Moreover, in case of quantitative studies, there is the possibility of motion artefacts during the acquisition of the input function, which requires processing software with the capability of single frame realignment $[57,96]$. This is probably one of the biggest technical challenges to quantitative cardiac PET. Particularly difficult to prevent and to correct is the presence of 'myocardial creep' due to pharmacologic stress [97]. Another major issue in quantitative PET is the quality of the injected bolus, which should show a single peak without evidence of detector saturation [98]. The time-activity curve should be examined to identify these possible interfering issues including a delayed start of the acquisition [98]. Moreover, patient motion can be detected as an abnormal hump in the later phases of the myocardial time-activity curve [98]. A general pitfall with the use of retention tracers ${ }^{82} \mathrm{Rb}$ and $\left[{ }^{13} \mathrm{~N}^{-N_{3}} \mathrm{H}_{3}\right.$ is that input function and myocardial wall delineation are performed on the late uptake images and then transferred to the early dynamic images. This approach may introduce artefacts, especially in case of 'myocardial creep', as VOIs may differ between the early part and the later part of the acquisition. For $\left[{ }^{15} \mathrm{O}\right]$ water, where there are no uptake images, VOIs need to be defined on the dynamic data itself and as such $\left[{ }^{15} \mathrm{O}\right]$ water is less sensitive to 'myocardial creep'-related artefacts. In any case, an effective means of identifying patient motion is to look at VOI placement over the myocardium during the course of the scan.

Independently of the above-mentioned potential pitfalls, the interpretation of the quantitative data might be hampered by a series of conditions, in which an abnormal peak MBF or (more frequently) an abnormal MFR is not directly an 
expression of myocardial ischaemia caused by epicardial CAD. In particular, patients with prior coronary artery bypass grafting (CABG) may have abnormal MBF in spite of patent grafts, although a trend towards normalisation after several months post-intervention has been described [99, 100]. Similarly, patients with LV dysfunction or severe kidney disease may have abnormal values without epicardial disease and with visual normal perfusion findings [101]. Conversely, patients with scar tissue due to prior myocardial infarction may present with abnormal low resting MBF causing false normal MFR values even if peak MBF is abnormal. In all these circumstances, the quantitative PET data must be cautiously evaluated. Image count density directly affects the diagnostic quality and reliability of the study. It is therefore important to realise that additional factors, such as body habitus and weight, radionuclide dose, scanner performance and acquisition time, also influence the final count density of PET images.

\section{$\left[{ }^{15}\right.$ O]water}

Pitfalls of $\left[{ }^{15} \mathrm{O}\right]$ water are related to bolus delivery, PET resolution, relative count rate statistics, intermediate range of the positron, patient motion and suboptimal hyperaemia. For $\left[{ }^{15} \mathrm{O}\right]$ water, where there are no uptake images, VOIs need to be defined on the dynamic data itself, and as such, $\left[{ }^{15} \mathrm{O}\right]$ water is less sensitive to 'myocardial creep'-related artefacts. In addition to the lack of uptake images, the main limitations for the analysis of $\left[{ }^{15} \mathrm{O}\right]$ water are the need to correct for the high activity in the blood pool and for the spill-over from LV and $\mathrm{RV}$ [102]. This correction is usually performed in the kinetic modelling and implemented in all available dedicated software packages that can process also $\left[{ }^{15} \mathrm{O}\right]$ water data. Specific commercial quantitative software programs for $\left[{ }^{15} \mathrm{O}\right]$ water PET have not been so far available, requiring inhouse knowledge of kinetic modelling for analysis. However, some packages are currently becoming commercially obtainable. Measurement of LVEF based on $\left[{ }^{15} \mathrm{O}\right]$ water can be done using first-pass images, but this has not been extensively validated at this point $[16,17]$. $\left[{ }^{15} \mathrm{O}\right]$ water PET MPI is clinically approved in Europe and reimbursed in several European countries. However, in the USA, $\left[{ }^{15} \mathrm{O}\right]$ water PET MPI has not been approved by the FDA for clinical use and is not reimbursed by third-party payers.

\section{${ }^{82} \mathbf{R b}$}

The specific pitfalls of ${ }^{82} \mathrm{Rb}$ imaging are related to the possibility of detector saturation during the tracer first pass and to the flattening of the blood first-pass curve caused by the decrease in activity of ${ }^{82} \mathrm{Rb}$ per volume with 'ageing' of the generator. Regarding the first point, optimised injection protocols taking into account the characteristics of the state-of- the-art scanners have been proposed, which offer a good compromise between the risk of detector saturation during the first-pass phase and the need of adequate activity in later frames [103, 104]. Regarding the second point, novel injectors with the capability to deliver constant activity infusion rates are now available [105]. Another peculiar problem of ${ }^{82} \mathrm{Rb}$ is the interference of the concurring prompt gamma emission, which happens in $13 \%$ of the decay events and requires a dedicated correction, with demonstrated favourable effects on image quality $[106,107]$. Finally, it must be remembered that the high energy ${ }^{82} \mathrm{Rb}$ positrons have the longest positron range among the myocardial PET tracers [20, 21, 108]. The lower extraction at high flow values could decrease the detectable difference between normally perfused and slightly hypoperfused myocardium under stress [108]. Abnormal tracer uptake in the lungs can be registered in patients with chronic obstructive pulmonary disease and in patients with LV dysfunction [109]. Gastric ${ }^{82} \mathrm{Rb}$ uptake and spill-over can be seen in up to $10 \%$ of patients and affect the analysis of the inferior wall on PET MPI [110]. Proton pump inhibitor therapy seems to be associated with an increase in the intensity of the gastric ${ }^{82} \mathrm{Rb}$ activity [110]. In addition, obesity and large stomach volumes were associated with more severe impact of the gastric signal on the PET MPI analysis, suggesting that appropriate fasting prior to ${ }^{82} \mathrm{Rb}$ PET MPI may help to improve image quality, in particular in obese patients [111].

\section{$\left[{ }^{13}{\mathrm{~N}] \mathrm{NH}_{3}}\right.$}

In addition to the general pitfalls of PET MPI, $\left[{ }^{13} \mathrm{~N} \mathrm{NH}_{3}\right.$ has some specific issues. In particular, the regional uptake can be relatively reduced in the lateral wall, mainly in subjects with normal LV function [112]. More recent studies suggest that a major role in this finding is played by attenuation artefacts related to respiratory movements [113]. Apical thinning has been reported in PET MPI in general, but it is more pronounced with $\left[{ }^{13} \mathrm{~N}_{\mathrm{NH}}\right.$ and in TOF cameras $[114,115]$. As with ${ }^{82} \mathrm{Rb}$, abnormal tracer uptake in the lungs can be observed in patients with chronic obstructive pulmonary disease and in patients with LV dysfunction. Moreover, increased pulmonary tracer uptake has been described in heavy smokers as well [116]. As for all other perfusion tracers (PET as well as SPECT), abnormal visualisation of the RV wall can be observed in case of hypertrophy or because of chronic obstructive lung disease. If abnormal uptake in the RV wall is observed only under stress, it can be caused by a relatively lower uptake in the left myocardium related to severe CAD with diffuse ischaemia. Specific pitfalls for quantitative perfusion measurements can be related to the misalignment of emission and $\mathrm{CT}$ images for attenuation correction and to motion artefacts during the dynamic acquisition. On the other hand, the relatively lower activity using $\left[{ }^{13} \mathrm{~N}^{-N_{3}} \mathrm{H}_{3}\right.$ as compared with ${ }^{82} \mathrm{Rb}$ reduces the risk of overflow and dead time losses during 
the first phases of bolus transit through the heart, and the higher quality of the uptake images with $\left[{ }^{13} \mathrm{~N}^{-N_{3}}\right.$ facilitates the definition of the VOIs needed for quantitative measurements. Because of the more prolonged half time, $\left[{ }^{13} \mathrm{~N}^{\mathrm{N} \mathrm{NH}_{3}}\right.$ protocols are more time demanding. Performing the resting studies of more than one patient and then returning to the first patient for the stress part can overcome this limitation. However, although this approach improves the patient throughput, it has the drawback of requiring placing each patient two times separately on the examination bed and increases the problems related to patient positioning and to $\mathrm{CT}$ alignment. Thus, shortened protocols with correction of residual activity have been proposed [48, 49]. For gated PET assessment, the differences in timing of the stress study using $\left[{ }^{13} \mathrm{~N}\right] \mathrm{NH}_{3}$ protocols must be taken into consideration.

\section{Clinical evidence}

\section{$\left[{ }^{15}\right.$ O]water}

Beyond its characteristics of ideal tracer for MBF quantitation, $\left[{ }^{15} \mathrm{O}\right]$ water PET has been thoroughly validated for the diagnosis of CAD. Because in the early days visual parametric images were difficult to obtain, the majority of the validation studies focused on optimal thresholds for hyperaemic MBF and MFR to differentiate between healthy persons and patients with CAD (Table 4). Normal values of $\left[{ }^{15} \mathrm{O}\right]$ water PET MPI have been studied, including the influence of different subject characteristics on normal MBF (and MFR) [125, 126]. $\left[{ }^{15} \mathrm{O}\right]$ water PET MPI with a hyperaemic MBF cut-off at $2.5 \mathrm{~mL} / \mathrm{min} / \mathrm{g}$ showed a $92 \%$ diagnostic accuracy for the detection of CAD using invasive coronary angiography (ICA) and fractional flow reserve (FFR) as reference [59]. In addition, hyperaemic MBF (cut-off $1.86 \mathrm{~mL} / \mathrm{min} / \mathrm{g}$ ) was more accurate (84\%) than MFR (cut-off 2.3, 74\%) for diagnosing CAD [60]. This superiority of hyperaemic MBF, although with slightly different thresholds, was confirmed in subsequent reports $[75,127]$. In these studies, the optimal cut-off value to detect FFR assessed obstructive CAD ranged between 2.3 and $2.4 \mathrm{~mL} / \mathrm{min} / \mathrm{g}$ for hyperaemic MBF and was 2.5 for MFR [75, 117, 127]. The higher diagnostic accuracy of hyperaemic MBF as compared with MFR paved the way for stress only protocols. In addition, the PACIFIC trial revealed that $\left[{ }^{15} \mathrm{O}\right]$ water PET had higher diagnostic accuracy than SPECT MPI or CCTA [76]. It is important to note that such prospective studies are currently lacking for other PET perfusion tracers and no head-to-head comparisons are currently available. In addition, it should be kept in mind that these results were obtained in patients suspected of CAD but without a previous history of CAD and with a normal LVEF. Studies on other patient populations such as the PACIFIC II are currently ongoing. In analogy to the mounting body of evidence in other PET perfusion tracers, $\left[{ }^{15} \mathrm{O}\right]$ water PET also holds strong prognostic information and is incremental to anatomical coronary abnormalities as documented by CCTA [128].

\section{${ }^{82} \mathrm{Rb}$}

Sensitivity and specificity for detecting an angiographically significant coronary stenosis of $>50 \%$ are $87 \%$ and $73 \%$ for SPECT MPI compared with $91 \%$ and $89 \%$ for ${ }^{82} \mathrm{Rb}$ MPI, respectively $[129,130]$. In a systematic review and metaanalysis evaluating the accuracy of ${ }^{82} \mathrm{Rb}$ MPI in comparison with SPECT MPI for the diagnosis of obstructive CAD, fifteen ${ }^{82} \mathrm{Rb}$ PET and eight cardiac SPECT studies were included [131]. ${ }^{82} \mathrm{Rb}$ PET demonstrated sensitivity and specificity of $90 \%$ and $88 \%$ for the detection of obstructive CAD on ICA, whereas the sensitivity and specificity for ${ }^{99 \mathrm{~m}} \mathrm{Tc}$-labelled tracer SPECT with ECG-gating and attenuation correction were $85 \%$ and $85 \%$, respectively [131]. When patients with low prevalence of CAD were excluded, diagnostic accuracy was higher with ${ }^{82} \mathrm{Rb}$ MPI than with SPECT MPI (area under the
Table 4 Proposed stress MBF and MFR threshold values for CAD detection

\begin{tabular}{llll}
\hline Reference & Tracer & Stress MBF cut-off & MFR cut-off \\
\hline Kajander S et al. [59] & {$\left[{ }^{15} \mathrm{O}\right]$ water } & $2.5 \mathrm{~mL} / \mathrm{min} / \mathrm{g}$ & \\
Danad I et al. [60] & {$\left[{ }^{15} \mathrm{O}\right]$ water } & $1.86 \mathrm{~mL} / \mathrm{min} / \mathrm{g}$ & 2.3 \\
Danad I et al. [117] & {$\left[{ }^{15} \mathrm{O}\right]$ water } & $2.2 \mathrm{~mL} / \mathrm{min} / \mathrm{g}$ & 2.5 \\
Danad I et al. [75] & {$\left[{ }^{15} \mathrm{O}\right]$ water } & $2.3 \mathrm{~mL} / \mathrm{min} / \mathrm{g}$ & 2.5 \\
Hajjiri MM et al. [118] & {$\left[{ }^{13} \mathrm{~N}_{\mathrm{NH}}\right.$} & $1.85 \mathrm{~mL} / \mathrm{min} / \mathrm{g}$ & 2 \\
Fiechter M et al. [119] & {$\left[{ }^{13} \mathrm{~N}_{3} \mathrm{NH}_{3}\right.$} & & 2 \\
Morton G et al. [120] & {$\left[{ }^{13} \mathrm{~N}\right] \mathrm{NH}_{3}$} & & 1.44 \\
Anagnostopoulos C et al. [121] & ${ }^{82} \mathrm{Rb}$ & $1.7 \mathrm{~mL} / \mathrm{min} / \mathrm{g}$ & 2 \\
Naya M et al. [122] & ${ }^{82} \mathrm{Rb}$ & & 2 \\
Naya M et al. [123] & ${ }^{82} \mathrm{Rb}$ & & 2 \\
Ziadi MC et al. [124] & ${ }^{82} \mathrm{Rb}$ & & 2
\end{tabular}


curve (AUC) 0.95 vs. $0.90 ; p<0.0001$ ) with a marked decrease in the specificity of SPECT MPI (70\%) [131]. Three studies compared directly ${ }^{82} \mathrm{Rb}$ MPI with SPECT MPI and found superior accuracy of ${ }^{82} \mathrm{Rb}$ MPI $[32,132,133]$. Moreover, ${ }^{82} \mathrm{Rb}$ MPI allowed for an effective prognostic patient risk stratification independently of the results of SPECT MPI [134]. A recent prospective study in women and obese patients confirmed the superior sensitivity of ${ }^{82} \mathrm{Rb}$ MPI compared with SPECT MPI even if acquired with a cadmium zinc telluride camera $-85 \%$ vs. $57 \%, p<0.05$ [135]. The addition of MBF quantification to the interpretation of MPI has proven clinically relevant, especially for the identification of patients with balanced myocardial ischaemia [121, 136, 137] (Table 4). Moreover, impaired MFR is associated with a worse prognosis in symptomatic patients with a visual normal PET MPI [122]. A value of global MFR $>1.9$ excludes highrisk CAD with a negative predictive value of $97 \%$ [123]. Conversely, the prevalence of multivessel disease is high in patients with global MFR $<1.5$ and intermediate for global MFR values between 1.5 and 2.0 with some overlap with microvascular disease [138]. In patients with an intermediate risk of mortality based on MPI, the addition of MFR allowed for the re-classification of $17 \%$ of patients into the high-risk group and $34 \%$ of patients into the low-risk group [138]. In addition, the decrease in global MFR values measured in 677 patients with ${ }^{82} \mathrm{Rb}$ PET had a strong and incremental prognostic value over the extent of myocardial ischaemia [124]. In patients with known or suspected CAD, a multicentre observational study showed that the extent and severity of ischaemia and scar on PET MPI provided incremental risk estimates of cardiac death and all-cause death compared with traditional coronary risk factors [139]. In contrast to cardiac SPECT, images are acquired with ${ }^{82} \mathrm{Rb}$ PET during the pharmacological stress. Subjects without CAD exhibit a rise in LVEF during pharmacological adenosine stress, whereas the absence of increase or even a drop in LVEF is associated with multivessel disease on ICA [72].

\section{$\left[{ }^{13} \mathrm{~N}\right] \mathrm{NH}_{3}$}

The clinical value of $\left[{ }^{13} \mathrm{~N}\right] \mathrm{NH}_{3}$ PET has been well demonstrated. Early studies based on visual and semi-quantitative analysis had already demonstrated the superiority over ${ }^{201} \mathrm{Tl}$ MPI in detecting myocardial ischaemia, and these results were confirmed using ${ }^{99 \mathrm{~m}}$ Tc-labelled tracers [37, 140]. Subsequent studies including quantitative perfusion data showed an excellent diagnostic performance of the measurements for CAD detection and indicated that MBF and MFR have an added value over the visual assessment of perfusion [141]. As a further demonstration of quantitative $\left[{ }^{13} \mathrm{~N}^{-N_{3}} \mathrm{H}_{3}\right.$ PET reliability in terms of test-re-test variation, several studies showed that this approach can detect signs of asymptomatic CAD in subjects with elevated risk profile and then recognise $\mathrm{MBF}$ improvement after that an effective control of the risk factors had been obtained [142-148]. More recent studies indicated the added value of quantitative $\left[{ }^{13} \mathrm{~N}\right] \mathrm{NH}_{3}$ PET for characterisation of multivessel CAD $[118,119]$. With regard to the prognostic implications of MBF and MFR measurements using $\left[{ }^{13} \mathrm{~N}\right] \mathrm{NH}_{3}$ PET, it was observed that these parameters were able to improve the prognostic stratification of subjects already classified according to their risk profile [149]. In a comparison between perfusion pattern and quantitative data, the adverse prognostic meaning of abnormal perfusion was confirmed, but a low MFR identified patients at risk of cardiac events even in case of normal perfusion pattern [150]. Similarly, the decrease in MFR was found to be a more sensitive predictor for cardiac death than LVEF, both in a general population of chronic $\mathrm{CAD}$ patients and in a cohort submitted to PET-driven revascularisation [151, 152]. Various studies have tried to assess the best thresholds to differentiate between normal and abnormal MBF and MFR in $\left[{ }^{13} \mathrm{~N}_{\mathrm{NH}_{3}}\right.$ PET (Table 4). In a direct comparison between hyperaemic MBF (cut-off $1.52 \mathrm{~mL} / \mathrm{min} / \mathrm{g}$ ) and MFR (cut-off 2.74), MFR showed a diagnostic superiority for detecting a significant coronary stenosis [141]. Subsequent studies indicated a threshold of $1.85 \mathrm{~mL} / \mathrm{min} / \mathrm{g}$ for hyperaemic MBF and of 2.0 for MFR [118]. In this last report, however, maximal MBF appeared more effective for detecting CAD than MFR [118]. On the other hand, the MFR cut-off of 2.0 was later confirmed [119]. In other studies, using a different quantification method, the MFR threshold was set at a lower level (1.4) [120].

\section{Clinical indications}

The value of quantitative PET for CAD diagnosis and prognosis has been extensively validated [153-155]. However, as in general for PET studies as compared with their SPECT equivalents, costs and logistic problems, including the current prevalent use of PET scanners for oncology indications, make it necessary to identify specific patient subsets who can mostly benefit from PET MPI.

\section{Diagnosis}

For diagnostic purposes, the most widely accepted indication for using quantitative PET is the suspicion of diffuse CAD, with the possibility of balanced ischaemia that could be missed by the assessment of relative tracer uptake. More in general, the added value of quantitative PET is accepted for patients with known $\mathrm{CAD}$, in whom a more in-depth pathophysiological assessment of the disease is required, or in whom complex, multivessel disease is suspected [156]. Conversely, quantitative PET is useful in all patients with symptoms suggestive of myocardial ischaemia, in whom ICA does not show significant lesions, in order to identify 
microvascular disease [137]. This is particularly relevant in female patients [157, 158]. Given the increasing use of CCTA, there is a growing number of patients in whom the detection of borderline lesions requires further assessment of possible ischaemic burden. Patients with high body mass index represent another accepted indication for using PET because image quality is improved due to the high energy photons, high signal of PET tracers and accurate attenuation correction of PET [159]. Because of the more favourable dosimetric profile, PET should be preferred in young patients, particularly in young women.

\section{Prognosis}

Several studies have demonstrated that quantification of MBF and MFR can be valuable for risk stratification [122-124, 138, $149-152,160,161]$. In this regard, there is evidence that quantitative PET, putting together several important prognostic indicators, such as the extent of regional uptake defects, peak MBF, MFR and LVEF reserve, could be very useful as a tool for stratifying risk in CAD patients [162]. However, the choice of using PET is affected by the above-mentioned logistic and economic limitations, taking into account that gated SPECT MPI allows as well for good risk stratification in patients with chest pain. On the other hand, in patients with other conditions that may affect the coronary circulation, such as the cardiomyopathies, and above all hypertrophic cardiomyopathy, quantitative PET with its unique capability to assess the severity of microvascular disease is probably the most effective method to achieve an effective risk stratification [163-166]. Furthermore, quantitative PET is able to improve the prognostic stratification of groups already at increased risk, such as diabetics and patients with end-stage renal disease, and even in patients with chest pain and normal coronary arteries, due to microvascular disease [167-170]. Finally, quantitative PET is the most effective way to identify vasculopathy in heart transplant patients [171].

\section{Treatment management}

Because of its capability to differentiate between the most severe stenosis and the other lesions, without missing even relatively limited reductions in coronary reserve, quantitative perfusion PET could be a very useful tool for guiding patient management, particularly in subjects with complex CAD $[172,173]$. Single-site experiences suggest even a costeffective capability to orient patient management [174]. Unfortunately, there are no randomised studies that assess the advantages of a PET-guided treatment strategy. Previous single-centre studies have demonstrated that quantitative PET data is able to identify asymptomatic CAD and to assess the results of therapy for risk factor management in these subjects $[142,143,145,146,148]$. More recently, differences in hyperaemic MBF and MFR between patients with resistant hypertension and those effectively treated have been demonstrated [65].

\section{Recommendations for PET MPI reports}

As expected, the construction of a correct report for a complex investigation such as quantitative cardiac PET is demanding. Table 5 summarises the items that should be included. Particular attention should be paid to a clear identification of the indication for the study, because this influences the emphasis that should be given to the several parameters that can be derived from the investigation. The accent on quantitative PET data does not make the value of the visual assessment of tracer uptake superfluous. The number of ischaemic or necrotic segments within the 17segment AHA classification, the SRS, SSS and SDS scores and the percentage of ischaemic burden should therefore be detailed. Similarly, it is necessary to describe wall motion abnormalities and report rest and stress LVEF values. As for the quantitative PET data, it is important to describe with utmost accuracy the technical modalities of the study, including the employed software and model, since these affect the final measurements and should be considered in case of comparison with prior reports, especially if produced by another centre. As mentioned above and apart from $\left[{ }^{15} \mathrm{O}\right]$ water, there is no consensus on the thresholds for normal and abnormal hyperaemic MBF or MFR for the different tracers, and it would be desirable to include those adopted, possibly with the proper reference. In case of $\left[{ }^{15} \mathrm{O}\right]$ water studies, the part about the visual assessment of tracer uptake in terms of semi-quantitative scores and gated PET data could be omitted. On the other hand, various groups using $\left[{ }^{15} \mathrm{O}\right]$ water consider positive for $\mathrm{CAD}$ any patient with at least two adjacent segments within a coronary territory classified as abnormal using a validated threshold (hyperaemic $\mathrm{MBF}<2.3 \mathrm{~mL} / \mathrm{g} / \mathrm{min}$ ), if this finding is confirmed by a visual defect in the parametric perfusion images [75]. Centres using hybrid imaging will include the data related to calcium scoring and possibly even those related to CCTA (see infra, "Hybrid imaging" section). The final conclusion of the report should include an interpretation of all reported findings and, most importantly, their connection in order to answer the specific clinical question. A particularly difficult point is the differentiation between balanced three-vessel myocardial ischaemia and diffuse microvascular disease. Among the possible criteria, a homogeneous reduction of MBF without detectable perfusion defects is considered more indicative of microvascular disease, whilst a more heterogeneous reduction is regarded as suggestive of balanced ischaemia due to CAD (Fig. 8). 
Table 5 Scheme for quantitative PET reporting

Administrative data

- Hospital name, including department, address, contacts

- Study identification number

Patient-specific information

- Patient identification, including personal data, sex, date of birth, height, weight, patient code and archive number

- Relevant history, including risk factor profile, previous cardiac events, prior revascularisation procedures, symptoms and current medications

- Indication for the study and specific clinical question to be answered by the investigation

Study-related data

- Type of study

- Study date

- Interpretation date

- Radiopharmaceutical, injected activity at rest and at stress, type of stress agent

- Acquisition protocol including description of dynamic parameters and framing of the gatedstudy

- Rest blood pressure and heart rate

- ECG at baseline

- Peak stress blood pressure and heart rate

- Presence of symptoms and ECG changes during the stress test

- Quality assessment of the acquired images

- Description of the processing software and compartmental model applied to the quantitative analysis

Image reporting

- Image description with visual analysis of resting and stress images, whenever available,with reference on the 17 -segment model for territory identification

- Scoring of the 17-segment model, with calculation of SRS, SSS and SDS (not for $\left[{ }^{15} \mathrm{O}\right]$ water)

- Definition of the perfusion normality vs. abnormality according to the accepted criteria taking care to assign the perfusion defects to the related coronary territory, according to the standard distribution or to the patient coronary distribution pattern if known

- Normal SSS $=0-3(<5 \%$ myocardium); mildly abnormal SSS $=4-7$ (5-10\% myocardium) moderately or severely abnormal SSS $>8(>10 \%$ myocardium) (not for $\left[{ }^{15} \mathrm{O}\right]$ water)

- Visual estimate of LV dimensions and transient ischaemic dilation

- Abnormal visualisation of the right ventricle and its possible enlargement

- Extracardiac findings, such as abnormal lung uptake (not for $\left[{ }^{15} \mathrm{O}\right]$ water)

Quantitative analysis

- Resting MBF (corrected for the rate pressure product if the resting heart rate and/or the baseline blood pressure is abnormally elevated) with range of the segmental values and both the single territory values and the global left ventricular value

- Stress MBF, described as above

- MFR described as above

- Summary of findings in term of segments/territories with peak MBF/MFR below the normal threshold (identified according to the tracer and the model used for data analysis)

Gated PET acquisition

- Resting LV volumes, EF and wall motion abnormalities, to be described qualitatively and scored with a proper point-scale in terms of motion and thickening according to the standard 17 -segment scheme

- Stress LV volumes, EF and wall motion abnormalities, to be described qualitatively and scored with a proper point-scale in terms of motion and thickening according to the standard 17 -segment scheme

- LVEF reserve

CT (images of adequate quality)

- Evaluation of coronary artery calcium scoring (description) and Agatston score; description of abnormal extracardiac findings on the CT

Hybrid PET/CCTA

- Correlation between MBF and the main findings of the CCTA (e.g. location of significant coronary obstructive disease and downstream MBF)

Conclusion

- Clinical interpretation of visual findings, MBF and MFR and gated PET data (whenever applicable)

- Specific answer to the clinical question, and if needed recommendation for additional imaging 


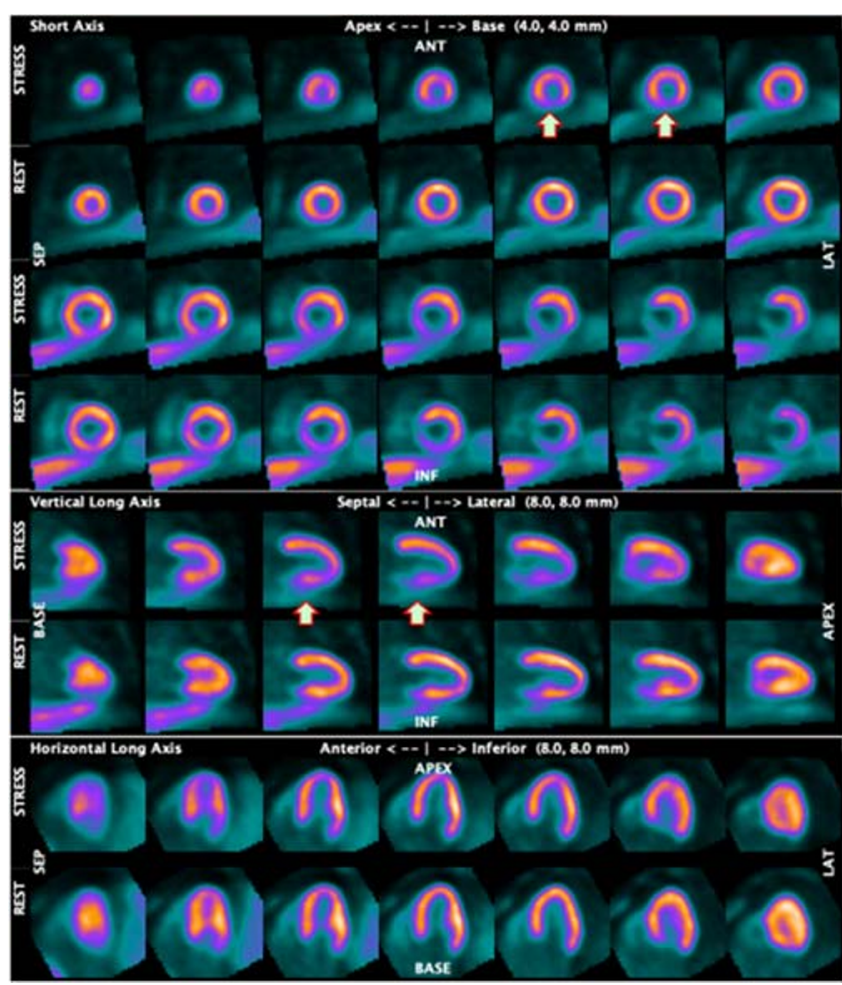

Fig. $8\left[{ }^{13} \mathrm{~N}^{2} \mathrm{NH}_{3}\right.$ PET of a patient with three-vessel disease. The uptake images (left panel) show a stress-induced inferior wall perfusion defect (arrows), which is confirmed by quantitative PET analysis (right panel), demonstrating clearly reduced stress $\mathrm{MBF}$ and decreased coronary flow reserve $(\mathrm{CFR}=\mathrm{MFR})$ in the right coronary artery territory $(\mathrm{RCA})$.

\section{Perspectives for PET MPI}

\section{Hybrid imaging}

Cardiac hybrid imaging offers the ability to combine strengths of different imaging modalities for anatomical and functional evaluation of CAD [175-177]. Hybrid images contain two datasets that are combined into a fused image in which both modalities contribute important information. This can be achieved with a hybrid scanner or with separate imaging systems by software-based image fusion. Hybrid scanners combining PET with a multidetector $\mathrm{CT}$, which can perform $\mathrm{CT}$ assessment of coronary anatomy, are becoming the standard for almost all commercially available devices [175]. In addition to CT, the newest generation of scanners offers the combination of PET with MRI [177].

CCTA has become an alternative to diagnostic ICA for the evaluation of many patients with suspected CAD. It shows very high sensitivity (>95\%) for the detection of coronary artery stenosis as compared with ICA [178, 179] and allows exclusion of obstructive CAD with high confidence. However, CCTA is a morphologic imaging tool that does not provide information on the haemodynamic consequences of a coronary artery stenosis. Thus, hybrid imaging combining CCTA and MPI may assist in differentiating

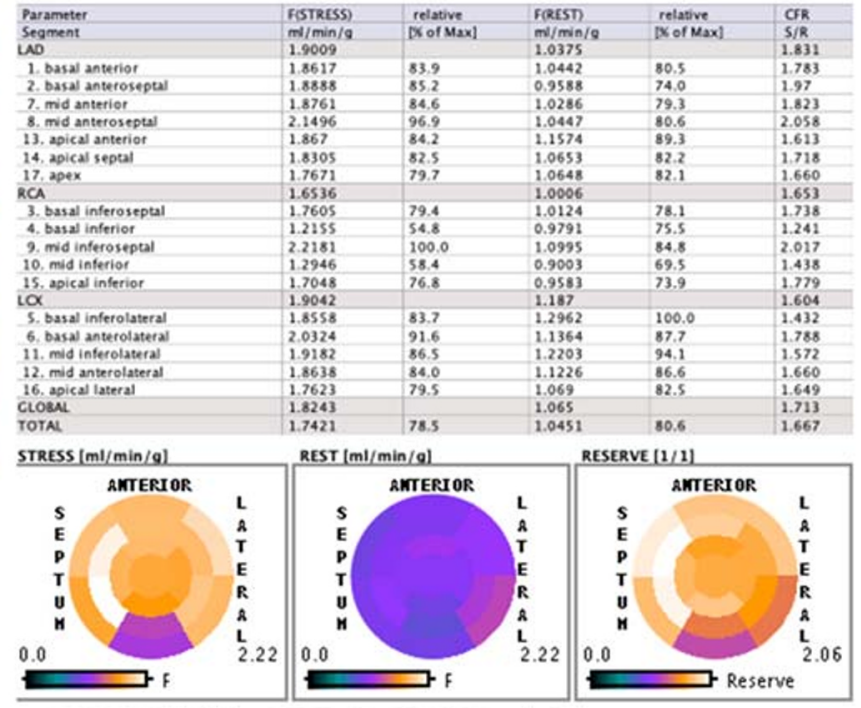

FLOW RESERVE | Pathology $<2.0$, Grey ZONe $2.0-2.5$. Normal $>2.51$

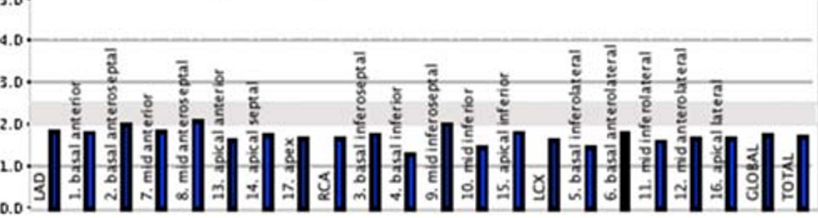

However, mildly abnormal stress MBF and MFR are observed in the left anterior descending (LAD) and left circumflex (LCX) territories as well. In gated PET analysis, LVEF decreased from 54\% at rest to $48 \%$ after stress, confirming the presence of diffuse ischaemia

haemodynamically significant from non-significant stenosis. Furthermore, assessment of coronary atherosclerotic burden by CT may improve the diagnostic and prognostic value of MPI [180-183].

Hybrid imaging can provide accurate spatial alignment of CT and MPI data to improve co-localisation of myocardial perfusion abnormalities and subtending coronary arteries (Fig. 9). Hybrid imaging studies have shown that standard distribution of myocardial territories corresponds with the real anatomic coronary tree in only $50-60 \%$ of cases, which may cause misleading interpretation [184].

\section{Hybrid imaging protocols}

Hybrid imaging is a relatively novel technology and there is still a need to clarify which patients can benefit most from hybrid imaging, how to optimally combine different modalities and what is the cost-effectiveness of hybrid imaging [175-177]. MPI and CCTA can be performed in a single session with PET/CT scanners that have a minimum of 64 detector rows. Alternatively, a coronary calcium scan without contrast injection obtained by electron-beam computed tomography (EBCT) or $\mathrm{CT}$ can be combined with perfusion imaging. Sequential testing, perfusion imaging followed by CCTA or CCTA followed by perfusion imaging, in selected 


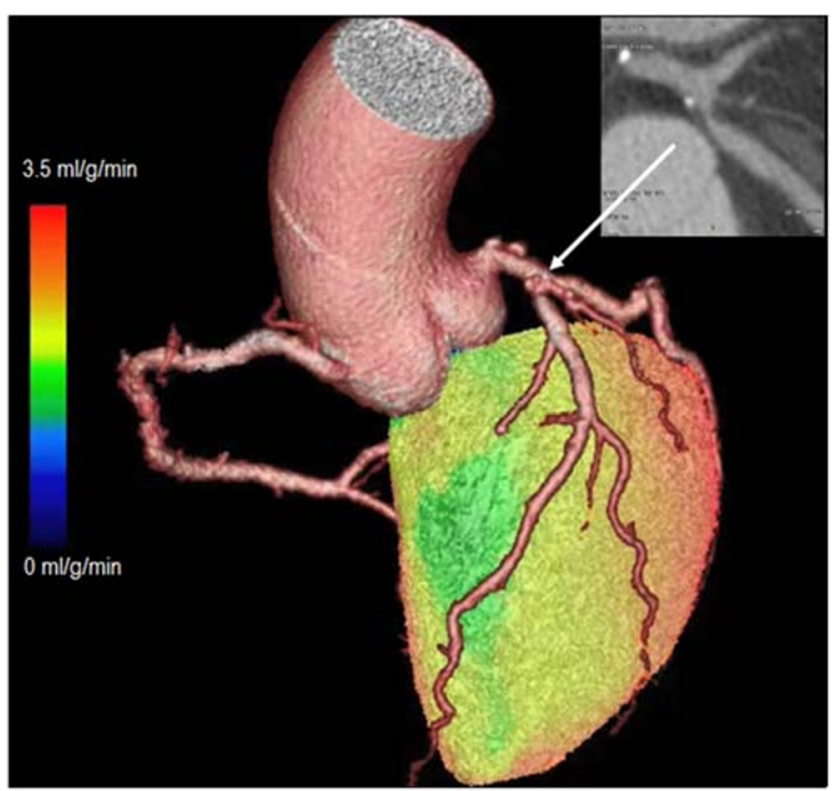

Fig. 9 Hybrid PET/CT image demonstrating 3D reconstruction of coronary anatomy and MBF. CCTA shows a stenosis in the proximal left anterior descending coronary artery (insert), and $\left[{ }^{15} \mathrm{O}\right]$ water PET shows reduced MBF (green colour) in the myocardium subtended by the artery during adenosine stress

patients with uncertain or equivocal findings in the first test, is also an option. Differentiation of obstructive CAD and microvascular dysfunction is possible only if both CCTA and perfusion imaging are performed. Whilst CCTA is currently recommended as the initial diagnostic test primarily in patients with a lower range of pre-test probability of CAD, it can be assumed that patients at the higher range of pre-test probability or with known CAD are those that will most likely benefit from evaluation of myocardial ischaemia [185].

Patient preparation and imaging protocols for CCTA, coronary calcium imaging and MPI are mainly the same as for the individual scans $[175,176,186]$. Although $\beta$-blocker may reduce the extent and severity of perfusion abnormalities [187], one study indicates that diagnostic accuracy of PET perfusion imaging was maintained in patients who received i.v. $\beta$-blocker to slow down the heart rate before CCTA [188]. Proper indications and possible contraindications, such as contrast allergy, should be reviewed separately for PET and CT studies [176]. Analysis software that is able to handle fused images and data should be used in addition to independent analysis of anatomic and functional images. Dedicated cardiac fusion software packages are now commercially available allowing hybrid imaging with an excellent interobserver reproducibility and short processing durations [189, 190]. These software packages, following automated/semiautomated segmentation, generate $3 \mathrm{D}$ reconstructions of myocardial perfusion data that are fused with 3D coronary anatomy datasets resulting in a hybrid 3D visualisation. Verification of adequate co-registration and possible manual correction is needed to avoid misalignment, because of mismatches in the respiratory phases between the two datasets, minor beat-to-beat variations in the heart position or different ventricular size in ECG-gated and non-gated datasets [175, $176,191]$.

\section{Radiation exposure}

Hybrid PET/CCTA imaging will increase the radiation dose to the patient since both techniques utilise ionising radiation. Using commonly available single-source 64-slice CT scanners with a prospectively ECG-triggered step-and-shoot acquisition protocol, it is possible to consistently perform a CCTA with an absorbed radiation dose of between 2 and $5 \mathrm{mSv}$ [192]. Coronary calcium scan adds less radiation (approximately $1 \mathrm{mSv}$ ) to the patient than CCTA $[175,176]$. Hybrid PET/MRI imaging can be performed with lower radiation exposure to the patient than PET/CT, which might be particularly beneficial in younger patients and/or in patients who may need repeated scans [177].

\section{Clinical evidence}

Validation studies have shown that cardiac hybrid PET/CT imaging is feasible and has high diagnostic accuracy in the detection of obstructive CAD [60, 126, 193-196]. A metaanalysis compared hybrid CCTA and perfusion imaging with SPECT, PET or MRI with CCTA alone (12 diagnostic studies and 951 patients in total) for the detection of CAD defined as luminal diameter reduction of at least $50 \%$ by ICA [197]. This meta-analysis found that pooled sensitivity of hybrid imaging was comparable to that of CCTA on per-patient (91\% vs. $90 \%$ ) and per-vessel (84\% vs. $89 \%$ ) basis. However, specificity of hybrid imaging clearly outperformed that of CCTA alone both on per-patient (93\% vs. 66\%) and on per-vessel (95\% vs. $83 \%$ ) analysis. There was also a modest improvement in overall diagnostic performance on per-vessel level (AUC 0.97 vs. 0.92). A limitation of the meta-analysis and current studies is that in many of them angiographic stenosis diameter is used as the reference standard instead of invasive FFR. The recent single-centre prospective PACIFIC trial compared hybrid imaging with stand-alone imaging in 208 patients who underwent CCTA, SPECT perfusion imaging and $\left[{ }^{15} \mathrm{O}\right]$ water PET perfusion imaging and ICA combined with measurement of FFR in all arteries [76]. In this study, the addition of functional imaging to CCTA improved specificity, but there was an increase in false negative findings that resulted in no overall incremental diagnostic benefit as compared with stand-alone imaging. However, studies comparing hybrid imaging with either stand-alone or side-by-side interpretation of the datasets have shown that interpretation was changed based on fused images in almost one-third of patients evaluated for suspected obstructive CAD [198-201]. 
Additional patient groups in which hybrid imaging has been shown to provide complementary information are those with congenital coronary anomalies [202] and patients with recurrent chest pain after CABG [203]. Furthermore, hybrid imaging can identify patients with microvascular dysfunction without obstructive CAD [204]. These studies indicate that the greatest added value of hybrid imaging is the exclusion of haemodynamic significance of coronary abnormalities seen on CCTA and the differentiation of epicardial and microvascular disease as well as correct localisation of the culprit lesion causing ischaemia.

The prognostic value of hybrid CCTA and SPECT MPI was demonstrated in a follow-up study in 324 patients [205]. A matched finding of myocardial ischaemia in a territory supplied by a stenotic coronary artery was associated with higher risk of death or myocardial infarction than unmatched ischaemia and stenosis. In another study, abnormal stress myocardial blood flow by $\left[{ }^{15} \mathrm{O}\right]$ water PET combined with stenosis on CCTA was associated with increased risk of death, myocardial infarction or unstable angina [206]. Revascularisation rates have also been highest in the presence of perfusion abnormality matched with a stenosis in the subtending coronary artery [207, 208].

Coronary artery calcium imaging can provide complementary information to MPI, because of its ability to quantify overall atherosclerotic burden [183, 209-213]. High atherosclerotic burden is associated with an increased likelihood of obstructive CAD $[209,211]$ and the risk of cardiac events in patients with normal myocardial perfusion scan [210], whereas a coronary artery calcium score of 0 identifies a low-risk patient population [183]. Coronary artery calcium score is inversely associated with both hyperaemic MBF and MFR providing incremental information over established CAD risk factors for predicting coronary vascular dysfunction [212, 213].

Hybrid PET/MR scanners have been available for a relatively short time due to technical challenges in this setup [177]. Different $\left[{ }^{18} \mathrm{~F}\right] \mathrm{FDG}$ administration protocols have shown potential for multimodality PET/MR evaluation of cardiac infiltration in multiorgan disease [214, 215], myocardial viability $[216,217]$ and inflammation $[218,219]$. However, the experience from myocardial perfusion imaging with PET/ MR scanners is limited [177]. The use of ${ }^{82} \mathrm{Rb}$ for PET/MR protocols is difficult, since the ${ }^{82} \mathrm{Rb}$ generator is not compatible with the MR setting. $\left[{ }^{18} \mathrm{~F}\right]$ flurpiridaz (see below) with its longer half-life may be better suited for PET/MR studies to investigate the extent of myocardial infarcted area by MR and myocardial perfusion by PET.

\section{New radiotracers $\left(\left[{ }^{18} \mathrm{~F}\right]\right.$ flurpiridaz)}

$\left[{ }^{18} \mathrm{~F}\right]$ flurpiridaz is a novel PET MPI tracer labelled with ${ }^{18} \mathrm{~F}$ that binds to mitochondrial complex 1. Preclinical studies demonstrated $\left[{ }^{18} \mathrm{~F}\right]$ flurpiridaz PET MPI to have rapid uptake in the myocardium, prolonged retention and superior extraction vs. flow profiles compared with nuclear tracers used in SPECT MPI [220-225]. Due to its favourable half-life (i.e. $110 \mathrm{~min}),\left[{ }^{18} \mathrm{~F}\right]$ flurpiridaz may be produced as a unit dose from a regional cyclotron, thus obviating the need for an onsite cyclotron or generator $[35,108]$. Phase $1\left[{ }^{18} \mathrm{~F}\right]$ flurpiridaz studies have shown that this tracer is clinically safe, has acceptable clinical dosimetry, and provides high-quality images in conjunction with exercise treadmill testing as well as pharmacological coronary vasodilation stress testing [226, 227]. Preliminary data suggested as well a potential value for quantitative assessments including MBF and MFR [94, 223].

A phase 2 study, BMS747158-201, consisting of 2 cohorts, was conducted to develop and subsequently to evaluate the diagnostic performance of 1-day rest/stress PET imaging protocols in patients with known or suspected CAD. An initial cohort was used to identify the appropriate activity and timing of $\left[{ }^{18} \mathrm{~F}\right]$ flurpiridaz injection for a 1-day rest/stress protocol. In the second cohort, 143 patients presenting with a broad spectrum of pre-test likelihood of CAD were enrolled to evaluate the sensitivity, specificity and accuracy of $\left[{ }^{18} \mathrm{~F}\right]$ flurpiridaz with the optimised 1-day rest/stress protocol; ICA or 3month follow-up for cardiac events was used as the reference standard. Of the 143 subjects enrolled, 125 had an interpretable scan. PET MPI sensitivity was $76.9 \%$ for all readers, and specificity ranged from 74.0 to $87.7 \%$. SPECT MPI sensitivity ranged from 59.6 to $71.2 \%$, and specificity ranged from 76.7 to $89.0 \%$ [228].

The phase 3 study BMS747158-301 (ClinicalTrials.gov Identifier: NCT01347710) was an open-label, international multicentre study for the assessment of CAD using $\left[{ }^{18} \mathrm{~F}\right]$ flurpiridaz PET MPI compared with SPECT MPI in patients with suspected or known CAD who were referred for ICA. Patients underwent a 1-day rest/stress protocol with ICA used as gold standard. The primary objective of this study was to assess the diagnostic efficacy (sensitivity and specificity) of $\left[{ }^{18} \mathrm{~F}\right]$ flurpiridaz injection PET MPI compared with SPECT MPI. A total of 755 patients had evaluable rest and stress SPECT MPI and $\left[{ }^{18} \mathrm{~F}\right]$ flurpiridaz PET MPI procedures as well as reference ICA. Although statistically significant superiority in sensitivity was demonstrated for $\left[{ }^{18} \mathrm{~F}\right]$ flurpiridaz PET MPI over SPECT MPI across readers $(p<0.001)$, the endpoint of demonstrating the non-inferiority of $\left[{ }^{18} \mathrm{~F}\right]$ flurpiridaz PET MPI to SPECT MPI in specificity was not met, with $\left[{ }^{18} \mathrm{~F}\right]$ flurpiridaz PET MPI reaching a specificity of $76.2 \%$, compared with SPECT MPI specificity of $86.8 \%$. Thus, another phase III trial (AURORA, ClinicalTrials.gov Identifier: NCT03354273) is currently ongoing, with the purpose to get the final approval for the clinical use of $\left[{ }^{18} \mathrm{~F}\right]$ flurpiridaz. However, a most recent retrospective evaluation on a cohort of the first phase 3 study has demonstrated that stress MBF quantified using $\left[{ }^{18} \mathrm{~F}\right]$ flurpiridaz and the previously validated 
two-tissue compartment model are able to accurately identify CAD both on a per-patient and a per-vessel basis [94, 223, 229].

Acknowledgements The guidelines were brought to the attention of the relevant EANM Committees and the National Societies of Nuclear Medicine. The comments and suggestions from the EANM Infection and Inflammation, Neuroimaging, Thyroid, Radiopharmacy, Technologist and Translational Molecular Imaging \& Therapy Committees and the Danish National Society are highly appreciated and have been considered for this Guideline.

Funding Open access funding provided by Università degli Studi di Firenze within the CRUI-CARE Agreement.

\section{Compliance with ethical standards}

Conflict of interest Mark Lubberink is co-founder and part-time employee of MedTrace Pharma A/S. Fabien Hyafil is consultant for Naogen. Antti Saraste is supported by grants from the Finnish Cardiovascular Foundation and Academy of Finland, has received consulting fees from Astra Zeneca and Amgen, and has received speaker fees from Astra Zeneca, Abbott, Amgen, Bayer and Novartis. All the other authors declare that they have no conflict of interest.

Ethical approval This article does not contain any studies with human participants or animals performed by any of the authors.

Liability statement This guideline summarises the views of the EANM Cardiovascular Committee. It reflects recommendations for which the EANM cannot be held responsible. The recommendations should be taken into context of good practice of nuclear medicine and do not substitute for national and international legal or regulatory provisions.

Open Access This article is licensed under a Creative Commons Attribution 4.0 International License, which permits use, sharing, adaptation, distribution and reproduction in any medium or format, as long as you give appropriate credit to the original author(s) and the source, provide a link to the Creative Commons licence, and indicate if changes were made. The images or other third party material in this article are included in the article's Creative Commons licence, unless indicated otherwise in a credit line to the material. If material is not included in the article's Creative Commons licence and your intended use is not permitted by statutory regulation or exceeds the permitted use, you will need to obtain permission directly from the copyright holder. To view a copy of this licence, visit http://creativecommons.org/licenses/by/4.0/.

\section{References}

1. Brunken RC, Schelbert HR. Positron emission tomography in clinical cardiology. Cardiol Clin. 1989;7:607-29.

2. Schelbert HR, Phelps ME, Huang SC, MacDonald NS, Hansen H, Selin C, et al. N-13 ammonia as an indicator of myocardial blood flow. Circulation. 1981;63:1259-72.

3. Bergmann SR, Fox KA, Rand AL, McElvany KD, Welch MJ, Markham J, et al. Quantification of regional myocardial blood flow in vivo with $\mathrm{H}_{2}{ }^{15} \mathrm{O}$. Circulation. 1984;70:724-33.

4. Krivokapich J, Smith GT, Huang SC, Hoffman EJ, Ratib O, Phelps ME, et al. ${ }^{13} \mathrm{~N}$ ammonia myocardial imaging at rest and with exercise in normal volunteers: quantification of absolute myocardial perfusion with dynamic positron emission tomography. Circulation. 1989;80:1328-37.

5. Huang SC, Williams BA, Krivokapich J, Araujo L, Phelps ME, Schelbert HR. Rabbit myocardial ${ }^{82} \mathrm{Rb}$ kinetics and a compartmental model for blood flow estimation. Am J Phys. 1989;256(4 Pt 2):H1156-64.

6. Renaud JM, Yip K, Guimond J, Trottier M, Pibarot P, Turcotte E, et al. Characterization of 3-dimensional PET systems for accurate quantification of myocardial blood flow. J Nucl Med. 2017;58: 103-9.

7. Lewellan T. Time-of-flight PET. Semin Nucl Med. 1998;28:26875.

8. Yamamoto M, Ficke DC, Ter-Pogossian MM. Experimental assessment of the gain achieved by the utilization of time-of-flight information in a positron emission tomograph (super PETT I). IEEE Trans Med Imaging. 1982;1:187-92.

9. NEMA Standards publication NU 2-2012: performance measurements of positron emission tomographs. Washington: National Electrical Manufacturers Association, 2012.

10. Conti M. Effects of randoms on signal-to-noise ratio in TOF PET. IEEE Trans Nucl Sci. 2006;53:1188-93.

11. Armstrong IS, Tonge CM, Arumugam P. Assessing time-of-flight signal-to-noise ratio gains within the myocardium and subsequent reductions in administered activity in cardiac PET studies. J Nucl Cardiol. 2019;26:405-12.

12. Suda M, Onoguchi M, Tomiyama T, Ishihara K, Takahashi N, Sakurai M, et al. The reproducibility of time-of-flight PET and conventional PET for the quantification of myocardial blood flow and coronary flow reserve with $\mathrm{N}-13$ ammonia. J Nucl Cardiol. 2016;23:457-72.

13. Hsu DFC, Ilan E, Peterson WT, Uribe J, Lubberink M, Levin CS. Studies of a next-generation silicon-photomultiplier-based timeof-flight PET/CT system. J Nucl Med. 2017;58:1511-8.

14. Rausch I, Ruiz A, Valverde-Pascual I, Cal-González J, Beyer T, Carrio I. Performance evaluation of the Vereos PET/CT system according to the NEMA NU2-2012 standard. J Nucl Med. 2019;60:561-7.

15. van Sluis J, de Jong J, Schaar J, Noordzij W, van Snick P, Dierckx $\mathrm{R}$, et al. Performance characteristics of the digital biograph vision PET/CT system. J Nucl Med. 2019;60:1031-6.

16. Driessen RS, van Timmeren JE, Stuijfzand WJ, Rijnierse MT, Danad I, Raijmakers PG, et al. Measurement of LV volumes and function using oxygen- 15 water-gated PET and comparison with CMR imaging. JACC Cardiovasc Imaging. 2016;9:1472-4.

17. Nordström J, Kero T, Harms HJ, Widström C, Flachskampf FA, Sörensen J, et al. Calculation of left ventricular volumes and ejection fraction from dynamic cardiac-gated ${ }^{15} \mathrm{O}$-water PET/CT: 5DPET. EJNMMI Phys. 2017;4:26.

18. Schindler TH, Dilsizian V. PET-determined hyperemic myocardial blood flow: further progress to clinical application. J Am Coll Cardiol. 2014;64:1476-8.

19. Iguchi S, Moriguchi T, Yamazaki M, Hori Y, Koshino K, Toyoda $\mathrm{K}$, et al. System evaluation of automated production and inhalation of ${ }^{15} \mathrm{O}$-labeled gaseous radiopharmaceuticals for the rapid ${ }^{15}$ O-oxygen PET examinations. EJNMMI Phys. 2018;5:37.

20. Partridge M, Spinelli A, Ryder W, Hindorf C. The effect of $\beta+$ energy on performance of a small animal PET camera. Nucl Instrum Methods Phys Res Sect A. 2006;568:933-6.

21. Sánchez-Crespo A, Andreo P, Larsson SA. Positron flight in human tissues and its influence on PET image spatial resolution. Eur J Nucl Med Mol Imaging. 2004;31:44-51.

22. Iida H, Rhodes CG, De Silva R, Yamamoto Y, Araujo LI, Maseri A, et al. Myocardial tissue fraction - correction for partial volume effects and measure of tissue viability. J Nucl Med. 1991;32: 2169-75. 
23. Yamamoto Y, De Silva R, Rhodes CG, Araujo LI, Iida H, Rechavia E, et al. A new strategy for the assessment of viable myocardium and regional myocardial blood flow using ${ }^{15} \mathrm{O}$-water and dynamic positron emission tomography. Circulation. 1992;86:167-78.

24. Einstein AJ. Radiation risk from coronary artery disease imaging: how do different diagnostic tests compare? Heart. 2008;94:151921.

25. Lubberink M, Harms HJ, Halbmeijer R, de Haan S, Knaapen P, Lammertsma AA. Low-dose quantitative myocardial blood flow imaging using ${ }^{15} \mathrm{O}$-water and PET without attenuation correction. J Nucl Med. 2010;51:575-80.

26. Mattsson S, Johansson L, Leide Svegborn S, Liniecki J, Noßke D, Riklund $\mathrm{K} \AA$, et al. Radiation dose to patients from radiopharmaceuticals: a compendium of current information related to frequently used substances. Ann ICRP. 2015;44(2 Suppl):7-321.

27. Selwyn AP, Allan RM, L'Abbate A, Horlock P, Camici P, Clark J, et al. Relation between regional myocardial uptake of rubidium-82 and perfusion: absolute reduction of cation uptake in ischemia. Am J Cardiol. 1982;50:112-21.

28. Goldstein RA, Mullani NA, Marani SK, Fisher DJ, Gould KL, O'Brien HA Jr. Myocardial perfusion with rubidium-82. II. Effects of metabolic and pharmacologic interventions. J Nucl Med. 1983;24:907-15.

29. Prior JO, Allenbach G, Valenta I, Kosinski M, Burger C, Verdun FR, et al. Quantification of myocardial blood flow with ${ }^{82} \mathrm{Rb}$ positron emission tomography: clinical validation with ${ }^{15} \mathrm{O}$-water. Eur J Nucl Med Mol Imaging. 2012;39:1037-47.

30. Hsu B, Hu LH, Yang BH, Chen LC, Chen YK, Ting CH, et al. SPECT myocardial blood flow quantitation toward clinical use: a comparative study with ${ }^{13} \mathrm{~N}$-Ammonia PET myocardial blood flow quantitation. Eur J Nucl Med Mol Imaging. 2017;44:117-28.

31. Gould KL, Goldstein RA, Mullani NA, Kirkeeide RL, Wong WH, Tewson TJ, et al. Noninvasive assessment of coronary stenoses by myocardial perfusion imaging during pharmacologic coronary vasodilation. VIII. Clinical feasibility of positron cardiac imaging without a cyclotron using generator-produced rubidium-82. J Am Coll Cardiol. 1986;7:775-89.

32. Go RT, Marwick TH, MacIntyre WJ, Saha GB, Neumann DR, Underwood DA, et al. A prospective comparison of rubidium-82 PET and thallium-201 SPECT myocardial perfusion imaging utilizing a single dipyridamole stress in the diagnosis of coronary artery disease. J Nucl Med. 1990;31:1899-905.

33. Case JA, deKemp RA, Slomka PJ, Smith MF, Heller GV, Cerqueira MD. Status of cardiovascular PET radiation exposure and strategies for reduction: an information statement from the Cardiovascular PET Task Force. J Nucl Cardiol. 2017;24:142739.

34. Walsh WF, Fill HR, Harper PV. Nitrogen-13-labeled ammonia for myocardial imaging. Semin Nucl Med. 1977;7:59-66.

35. Maddahi J, Packard RRS. Cardiac PET perfusion tracers: current status and future directions. Semin Nucl Med. 2014;44:333-43.

36. Hsu B. PET tracers and techniques for measuring myocardial blood flow in patients with coronary artery disease. J Biomed Res. 2013;27:452-9.

37. Husmann L, Wiegand M, Valenta I, Gaemperli O, Schepis T, Siegrist PT, et al. Diagnostic accuracy of myocardial perfusion imaging with single photon emission computed tomography and positron emission tomography: a comparison with coronary angiography. Int J Card Imaging. 2008;24:511-8.

38. Muzik O, Beanlands RS, Hutchins GD, Manger TJ, Nguyen N, Schwaiger M. Validation of nitrogen-13-ammonia tracer kinetic model for quantification of myocardial blood flow using PET. J Nucl Med. 1993;34:83-91.

39. DeGrado TR, Hanson MW, Turkington TG, Delong DM, Brezinski DA, Vallée JP, et al. Estimation of myocardial blood flow for longitudinal studies with ${ }^{13} \mathrm{~N}$-labeled ammonia and positron emission tomography. J Nucl Cardiol. 1996;3:494-507.

40. Hutchins GD, Schwaiger M, Rosenspire KC, Krivokapich J, Schelbert H, Kuhl DE. Noninvasive quantification of regional blood flow in the human heart using N-13 ammonia and dynamic positron emission tomographic imaging. J Am Coll Cardiol. 1990;15:1032-42.

41. Verberne HJ, Acampa W, Anagnostopoulos C, Ballinger J, Bengel F, De Bondt P, et al. EANM procedural guidelines for radionuclide myocardial perfusion imaging with SPECT and SPECT/CT: 2015 revision. Eur J Nucl Med Mol Imaging. 2015;42:1929-40.

42. Tadamura E, Iida H, Matsumoto K, Mamede M, Kubo S, Toyoda $\mathrm{H}$, et al. Comparison of myocardial blood flow during dobutamine-atropine infusion with that after dipyridamole administration in normal men. J Am Coll Cardiol. 2001;37:130-6.

43. Skopicki HA, Abraham SA, Picard MH, Alpert NM, Fischman AJ, Gewirtz H. Effects of dobutamine at maximally tolerated dose on myocardial blood flow in humans with ischemic heart disease. Circulation. 1997;96:3346-52.

44. Iskandrian AE, Bateman TM, Belardinelli L, Blackburn B, Cerqueira MD, Hendel RC, et al. Adenosine versus regadenoson comparative evaluation in myocardial perfusion imaging: results of the ADVANCE phase 3 multicenter international trial. J Nucl Cardiol. 2007;14:645-58.

45. Vleeming EJ, Lazarenko SV, van der Zant FM, Pan XB, Declerck $\mathrm{JM}$, Wondergem $\mathrm{M}$, et al. Cardiac displacement during ${ }^{13} \mathrm{~N}-\mathrm{am}$ monia myocardial perfusion PET/CT: comparison between adenosine- and regadenoson-induced stress. J Nucl Med Technol. 2018;46:114-22.

46. Memmott MJ, Tonge CM, Saint KJ, Arumugam P. Impact of pharmacological stress agent on patient motion during rubidium82 myocardial perfusion PET/CT. J Nucl Cardiol. 2018;25:128695.

47. Goudarzi B, Fukushima K, Bravo P, Merrill J, Bengel FM. Comparison of the myocardial blood flow response to regadenoson and dipyridamole: a quantitative analysis in patients referred for clinical ${ }^{82} \mathrm{Rb}$ myocardial perfusion PET. Eur J Nucl Med Mol Imaging. 2011;38:1908-16.

48. Markousis-Mavrogenis G, Juárez-Orozco LE, Alexanderson E. Residual activity correction in quantitative myocardial perfusion ${ }^{13} \mathrm{~N}$-ammonia PET imaging: a study in post-MI patients. Hell J Cardiol. 2017;58:245-9.

49. Opstal TSJ, Knol RJJ, Cornel JH, Wondergem M, van der Zant FM. Myocardial blood flow and myocardial flow reserve values in ${ }^{13} \mathrm{~N}$-ammonia myocardial perfusion PET/CT using a timeefficient protocol in patients without coronary artery disease. Eur J Hybrid Imaging. 2018;2:11. https://doi.org/10.1186/s41824018-0029-z.

50. Moody JB, Lee BC, Corbett JR, Ficaro EP, Murthy VL. Precision and accuracy of clinical quantification of myocardial blood flow by dynamic PET: a technical perspective. J Nucl Cardiol. 2015;22: 935-51.

51. Søndergaard HM, Madsen MM, Boisen K, Bøttcher M, Schmitz $\mathrm{O}$, Nielsen TT, et al. Evaluation of iterative reconstruction (OSEM) versus filtered back-projection for the assessment of myocardial glucose uptake and myocardial perfusion using dynamic PET. Eur J Nucl Med Mol Imaging. 2007;34:320-9.

52. Armstrong IS, Tonge CM, Arumugam P. Impact of point spread function modeling and time-of-flight on myocardial blood flow and myocardial flow reserve measurements for rubidium- 82 cardiac PET. J Nucl Cardiol. 2014;21:467-74.

53. Souvatzoglou M, Bengel F, Busch R, Kruschke C, Fernolendt H, Lee D, et al. Attenuation correction in cardiac PET/CT with three different CT protocols: a comparison with conventional PET. Eur J Nucl Med Mol Imaging. 2007;34:1991-2000. 
54. McQuaid SJ, Hutton BF. Sources of attenuation-correction artefacts in cardiac PET/CT and SPECT/CT. Eur J Nucl Med Mol Imaging. 2008;35:1117-23.

55. De Man B, Nuyts J, Dupont P, Marchal G, Suetens P. Reduction of metal streak artefacts in X-ray computed tomography using a transmission maximum a posteriori algorithm. IEEE Trans Nucl Sci. 2000;47:977-81.

56. Slomka PJ, Rubeaux M, Le Meunier L, Dey D, Lazewatsky JL, Pan T, et al. Dual-gated motion-frozen cardiac PET with flurpiridaz F 18. J Nucl Med. 2015;56:1876-81.

57. Hunter CRRN, Klein R, Beanlands RS, deKemp RA. Patient motion effects on the quantification of regional myocardial blood flow with dynamic PET imaging. Med Phys. 2016;43:1829.

58. Armstrong IS, Memmott MJ, Saint KJ, Saillant A, Hayden C, Arumugam P. Assessment of motion correction in dynamic rubidium-82 cardiac PET with and without frame-by-frame adjustment of attenuation maps for calculation of myocardial blood flow. J Nucl Cardiol. 2019. https://doi.org/10.1007/s12350-01901834-5.

59. Kajander S, Joutsiniemi E, Saraste M, Pietilä M, Ukkonen H, Saraste A, et al. Cardiac positron emission tomography/ computed tomography imaging accurately detects anatomically and functionally significant coronary artery disease. Circulation. 2010;122:603-13.

60. Danad I, Raijmakers PG, Appelman YE, Harms HJ, de Haan S, van den Oever ML, et al. Hybrid imaging using quantitative $\mathrm{H}_{2}{ }^{15} \mathrm{O}$ PET and CT-based coronary angiography for the detection of coronary artery disease. J Nucl Med. 2013;54:55-63.

61. Sciagrà R, Calabretta R, Cipollini F, Passeri A, Castello A, Cecchi F, et al. Myocardial blood flow and left ventricular functional reserve in hypertrophic cardiomyopathy: a ${ }^{13} \mathrm{NH}_{3}$ gated PET study. Eur J Nucl Med Mol Imaging. 2017;44:866-75.

62. El Fakhri G, Sitek A, Guerin B, Kijewski MF, Di Carli MF, Moore SC. Quantitative dynamic cardiac ${ }^{82}$ Rb PET using generalized factor and compartment analyses. J Nucl Med. 2005;46:1264-71.

63. Lortie M, Beanlands RSB, Yoshinaga K, Klein R, DaSilva JN, deKemp RA. Quantification of myocardial blood flow with ${ }^{82} \mathrm{Rb}$ dynamic PET imaging. Eur J Nucl Med Mol Imaging. 2007;34: 1765-74.

64. Dekemp RA, Declerck J, Klein R, Pan XB, Nakazato R, Tonge C, et al. Multisoftware reproducibility study of stress and rest myocardial blood flow assessed with 3D dynamic PET/CT and a 1tissue-compartment model of $82 \mathrm{Rb}$ kinetics. J Nucl Med. 2013;54:571-7.

65. Gaudieri V, Acampa W, Rozza F, Nappi C, Zampella E, Assante $\mathrm{R}$, et al. Coronary vascular function in patients with resistant hypertension and normal myocardial perfusion: a propensity score analysis. Eur Heart J Cardiovasc Imaging. 2019;20:949-58. https://doi.org/10.1093/ehjci/jez025.

66. Cerqueira MD, Weissman NJ, Dilsizian V, Jacobs AK, Kaul S, Laskey WK, et al. American Heart Association Writing Group on Myocardial Segmentation and Registration for Cardiac Imaging Standardized myocardial segmentation and nomenclature for tomographic imaging of the heart. Circulation. 2002;105:539-42.

67. Brophey MD, Farukhi IM, Castanon R, DeLaPena R, Bradshaw L, Banerjee S. Accuracy of ${ }^{82} \mathrm{Rb}$ PET/CT myocardial perfusion imaging with regadenoson stress, including 3-year clinical outcomes. J Nucl Med Technol. 2017;45:75-81.

68. Hsiao E, Ali B, Blankstein R, Skali H, Ali T, Bruyere J Jr, et al. Detection of obstructive coronary artery disease using regadenoson stress and ${ }^{82} \mathrm{Rb}$ PET/CT myocardial perfusion imaging. J Nucl Med. 2013;54:1748-54.

69. Dorbala S, Hachamovitch R, Curillova Z, Thomas D, Vangala D, Kwong RY, et al. Incremental prognostic value of gated Rb-82 positron emission tomography myocardial perfusion imaging over clinical variables and rest LVEF. JACC Cardiovasc Imaging. 2009;2:846-54.

70. Bravo PE, Chien D, Javadi M, Merrill J, Bengel FM. Reference ranges for LVEF and LV volumes from electrocardiographically gated ${ }^{82} \mathrm{Rb}$ cardiac PET/CT using commercially available software. J Nucl Med. 2010;51:898-905.

71. Slart RH, Bax JJ, de Jong RM, de Boer J, Lamb HJ, Mook PH, et al. Comparison of gated PET with MRI for evaluation of left ventricular function in patients with coronary artery disease. $\mathrm{J}$ Nucl Med. 2004;45:176-82.

72. Dorbala S, Vangala D, Sampson U, Limaye A, Kwong R, Di Carli MF. Value of vasodilator left ventricular ejection fraction reserve in evaluating the magnitude of myocardium at risk and the extent of angiographic coronary artery disease: an ${ }^{82} \mathrm{Rb}$ PET/CT study. $\mathrm{J}$ Nucl Med. 2007;48:349-58.

73. Bravo PE, Tahari A, Pozios I, Luo HC, Bengel FM, Wahl RL, et al. Apparent left ventricular cavity dilatation during PET/CT in hypertrophic cardiomyopathy: clinical predictors and potential mechanisms. J Nucl Cardiol. 2016;23:1304-14.

74. Yalçin H, Valenta I, Yalçin F, Corona-Villalobos C, Vasquez N, $\mathrm{Ra}$ J, et al. Effect of diffuse subendocardial hypoperfusion on left ventricular cavity size by ${ }^{13} \mathrm{~N}$-ammonia perfusion PET in patients with hypertrophic cardiomyopathy. Am J Cardiol. 2016;118: 1908-15.

75. Danad I, Uusitalo V, Kero T, Saraste A, Raijmakers PG, Lammertsma AA, et al. Quantitative assessment of myocardial perfusion in the detection of significant coronary artery disease: cutoff values and diagnostic accuracy of quantitative $\left[{ }^{[15)} \mathrm{O}^{\mathrm{O}} \mathrm{H}_{2} \mathrm{O}\right.$ PET imaging. J Am Coll Cardiol. 2014;64:1464-75.

76. Danad I, Raijmakers PG, Driessen RS, Leipsic J, Raju R, Naoum $\mathrm{C}$, et al. Comparison of coronary CT angiography, SPECT, PET, and hybrid imaging for diagnosis of ischemic heart disease determined by fractional flow reserve. JAMA Cardiol. 2017;2:1100-7.

77. Berti V, Sciagrà R, Neglia D, Pietilä $\mathrm{M}$, Scholte AJ, Nekolla $\mathrm{S}$, et al. Segmental quantitative myocardial perfusion with PET for the detection of significant coronary artery disease in patients with stable angina. Eur J Nucl Med Mol Imaging. 2016;43:1522-9.

78. Harms HJ, Knaapen P, de Haan S, Halbmeijer R, Lammertsma AA, Lubberink M. Automatic generation of absolute myocardial blood flow images using $\left[{ }^{15} \mathrm{O}\right] \mathrm{H}_{2} \mathrm{O}$ and a clinical PET/CT scanner. Eur J Nucl Med Mol Imaging. 2011;38:930-9.

79. Harms HJ, De Haan S, Knaapen P, Allaart CP, Lammertsma AA, Lubberink M. Parametric images of myocardial viability using a single ${ }^{15} \mathrm{O}-\mathrm{H}_{2} \mathrm{O}$ PET/CT scan. J Nucl Med. 2011;52:745-9.

80. Harms HJ, Nesterov SV, Han C, Danad I, Leonora R, Raijmakers PG, et al. Comparison of clinical non-commercial tools for automated quantification of myocardial blood flow using oxygen-15labelled water PET/CT. Eur Heart J Cardiovasc Imaging. 2014;15: 431-41.

81. Yoshida K, Mullani N, Gould KL. Coronary flow and flow reserve by PET simplified for clinical applications using rubidium82 or nitrogen-13-ammonia. J Nucl Med. 1996;37:1701-12.

82. Johnson NP, Gould KL. Integrating noninvasive absolute flow, coronary flow reserve, and ischemic thresholds into a comprehensive map of physiological severity. J Am Col Cardiol Imaging. 2012;5:430-40.

83. Herrero P, Markham J, Shelton ME, Weinheimer CJ, Bergmann SR. Noninvasive quantification of regional myocardial perfusion with rubidium-82 and positron emission tomography: exploration of a mathematical model. Circulation. 1990;82:1377-86.

84. Nesterov SV, Deshayes E, Sciagrà R, Settimo L, Declerck JM, Pan XB, et al. Quantification of myocardial blood flow in absolute terms using ${ }^{82} \mathrm{Rb}$ PET imaging: the RUBY-10 study. JACC Cardiovase Imaging. 2014;7:1119-27.

85. Tahari AK, Lee A, Rajaram M, Fukushima K, Lodge MA, Lee $\mathrm{BC}$, et al. Absolute myocardial flow quantification with ${ }^{82} \mathrm{Rb} \mathrm{PET} /$ 
CT: comparison of different software packages and methods. Eur J Nucl Med Mol Imaging. 2014;41:126-35.

86. Dunet V, Klein R, Allenbach G, Renaud J, deKemp RA, Prior JO. Myocardial blood flow quantification by Rb-82 cardiac PET/CT: A detailed reproducibility study between two semi-automatic analysis programs. J Nucl Cardiol. 2016;23:499-510.

87. Sunderland JJ, Pan XB, Declerck J, Menda Y. Dependency of cardiac rubidium-82 imaging quantitative measures on age, gender, vascular territory, and software in a cardiovascular normal population. J Nucl Cardiol. 2015;22:72-84.

88. Murthy VL, Lee BC, Sitek A, Naya M, Moody J, Polavarapu V, et al. Comparison and prognostic validation of multiple methods of quantification of myocardial blood flow with ${ }^{82} \mathrm{Rb}$ PET. J Nucl Med. 2014;55:1952-8.

89. Kuhle WG, Porenta G, Huang SC, Buxton D, Gambhir SS, Hansen $\mathrm{H}$, et al. Quantification of regional myocardial blood flow using ${ }^{13} \mathrm{~N}$-ammonia and reoriented dynamic positron emission tomographic imaging. Circulation. 1992;86:1004-17.

90. Hutchins GD, Caraher JM, Raylman RR. A region of interest strategy for minimizing resolution distortions quantitative myocardial PET studies. J Nucl Med. 1992;33:1243-50.

91. Khorsand A, Graf S, Pirich C, Muzik O, Kletter K, Dudczak R, et al. Assessment of myocardial perfusion by dynamic N-13 ammonia PET imaging: comparison of 2 tracer kinetic models. J Nucl Cardiol. 2005;12:410-7.

92. Slomka PJ, Alexanderson E, Jácome R, Jiménez M, Romero E, Meave A, et al. Comparison of clinical tools for measurements of regional stress and rest myocardial blood flow assessed with ${ }^{13} \mathrm{~N}$ ammonia PET/CT. J Nucl Med. 2012;53:171-81.

93. Monroy-Gonzalez AG, Juarez-Orozco LE, Han C, Vedder IR, García DV, Borra R, et al. Software reproducibility of myocardial blood flow and flow reserve quantification in ischemic heart disease: a ${ }^{13} \mathrm{~N}$-ammonia PET study. J Nucl Cardiol. 2019. https://doi. org/10.1007/s12350-019-01620-3.

94. Nekolla SG, Reder S, Saraste A, Higuchi T, Dzewas G, Preissel A, et al. Evaluation of the novel myocardial perfusion PET tracer ${ }^{18} \mathrm{~F}$ BMS747158-02: comparison to ${ }^{13} \mathrm{~N}$ ammonia and validation with microspheres in a pig model. Circulation. 2009;119:2333-42.

95. Rajaram M, Tahari AK, Lee AH, Lodge MA, Tsui B, Nekolla S, et al. Cardiac PET/CT misregistration causes significant changes in estimated myocardial blood flow. J Nucl Med. 2013;54:50- 4.

96. Piccinelli M, Votaw JR, Garcia EV. Motion correction and its impact on absolute myocardial blood flow measures with PET. Curr Cardiol Rep. 2018;20:34

97. Koenders SS, van Dijk JD, Jager PL, Ottervanger JP, Slump CH, van Dalen JA. Impact of regadenoson-induced myocardial creep on dynamic rubidium-82 PET myocardial blood flow quantification. J Nucl Cardiol. 2019;26:719-28.

98. Votaw JR, Packard RRS. Technical aspects of acquiring and measuring myocardial blood flow: method, technique, and QA. J Nucl Cardiol. 2018;25:665-70.

99. Campisi R, Czernin J, Karpman HL, Schelbert HR. Coronary vasodilatory capacity and flow reserve in normal myocardium supplied by bypass grafts late after surgery. Am J Cardiol. 1997;80:27-31.

100. Spyrou N, Khan MA, Rosen SD, Foale R, Davies DW, Sogliani F, et al. Persistent but reversible coronary microvascular dysfunction after bypass grafting. Am J Physiol Heart Circ Physiol. 2000;279: H2634-40.

101. Paz Y, Morgenstern R, Weinberg R, Chiles M, Bhatti N, Ali Z, et al. Relation of coronary flow reserve to other findings on positron emission tomography myocardial perfusion imaging and left heart catheterization in patients with end-stage renal disease being evaluated for kidney transplant. Am J Cardiol. 2017;120:1909-12.

102. Bol A, Melin JA, Vanoverschelde JL, Baudhuin T, Vogelaers D, De Pauw M, et al. Direct comparison of [13N]ammonia and
[15O]water estimates of perfusion with quantification of regional myocardial blood flow by microspheres. Circulation. 1993;87: $512-25$.

103. Kolthammer JA, Muzic RF. Optimized dynamic framing for PETbased myocardial blood flow estimation. Phys Med Biol. 2013;58: 5783.

104. Tout D, Tonge C, Muthu S, Arumugam P. Assessment of a protocol for routine simultaneous myocardial blood flow measurement and standard myocardial perfusion imaging with rubidium82 on a high-count rate positron emission tomography system. Nucl Med Commun. 2012;33:1202-11.

105. Klein R, Adler A, Beanlands RS, deKemp RA. Precisioncontrolled elution of a ${ }^{82} \mathrm{Sr} /{ }^{82} \mathrm{Rb}$ generator for cardiac perfusion imaging with positron emission tomography. Phys Med Biol. 2007;52:659-73.

106. Esteves FP, Nye JA, Khan A, Folks RD, Halkar RK, Garcia EV, et al. Prompt-gamma compensation in Rb-82 myocardial perfusion 3D PET/CT. J Nucl Cardiol. 2010;17:247-53.

107. Armstrong IS, Memmott MJ, Tonge CM, Arumugam P. The impact of prompt gamma compensation on myocardial blood flow measurements with rubidium-82 dynamic PET. J Nucl Cardiol. 2018;25:596-605.

108. Maddahi J. Properties of an ideal PET perfusion tracer: new PET tracer cases and data. J Nucl Cardiol. 2012;19(Suppl 1):S30-7.

109. Brown TL, Voicu C, Merrill J, Bengel FM. Pathophysiologic correlates of ${ }^{82} \mathrm{Rb}$ biodistribution in cardiac PET/CT. Eur J Nucl Med Mol Imaging. 2011;38:479-84.

110. Alzahrani AH, Arasaratnam P, Massalha S, Alenazy A, Lee A, Clarkin O, et al. Effect of proton pump inhibitors on rubidium-82 gastric uptake using positron emission tomography myocardial perfusion imaging. J Nucl Cardiol. 2019. https://doi.org/10.1007/ s12350-019-01954-y.

111. Rasmussen T, Kjær A, Hasbak P. Stomach interference in ${ }^{82} \mathrm{Rb}$ PET myocardial perfusion imaging. J Nucl Cardiol. 2019;26: 1934-42.

112. De Jong RM, Blanksma PK, Willemsen AT, Anthonio RL, Meeder JG, Pruim J, et al. Posterolateral defect of the normal human heart investigated with nitrogen-13-ammonia and dynamic PET. J Nucl Med. 1995;36:581-5.

113. Klingensmith WC 3rd, Noonan C, Goldberg JH, Buchwald D, Kimball JT, Manson SM. Decreased perfusion in the lateral wall of the left ventricle in PET/CT studies with ${ }^{13} \mathrm{~N}$-ammonia: evaluation in healthy adults. J Nucl Med Technol. 2009;37:215-9.

114. Steffen DA, Giannopoulos AA, Grossmann M, Messerli M, Schwyzer M, Gräni C, et al. "Apical thinning": relations between myocardial wall thickness and apical left ventricular tracer uptake as assessed with positron emission tomography myocardial perfusion imaging. J Nucl Cardiol. 2018. https://doi.org/10.1007/ s12350-018-1397-2.

115. Tomiyama T, Ishihara K, Suda M, Kanaya K, Sakurai M, Takahashi N, et al. Impact of time-of-flight on qualitative and quantitative analyses of myocardial perfusion PET studies using ${ }^{13} \mathrm{~N}$-ammonia. J Nucl Cardiol. 2015;22:998-1007.

116. Kagaya A, Fukuda H, Yoshida K, Endo M, Himi T, Niwayama H, et al. Pulmonary kinetics of ${ }^{13} \mathrm{~N}$-ammonia in smoking subjects - a quantitative study using dynamic PET. Kaku Igaku. 1992;29: 1099-106.

117. Danad I, Raijmakers PG, Harms HJ, Heymans MW, van Royen N, Lubberink $\mathrm{M}$, et al. Impact of anatomical and functional severity of coronary atherosclerotic plaques on the transmural perfusion gradient: a $\left[{ }^{15} \mathrm{O}_{\mathrm{H}} \mathrm{O}\right.$ PET study. Eur Heart J. 2014;35:2094-105.

118. Hajjiri MM, Leavitt MB, Zheng H, Spooner AE, Fischman AJ, Gewirtz H. Comparison of positron emission tomography measurement of adenosine-stimulated absolute myocardial blood flow versus relative myocardial tracer content for physiological 
assessment of coronary artery stenosis severity and location. JACC Cardiovasc Imaging. 2009;2:751-8.

119. Fiechter M, Ghadri JR, Gebhard C, Fuchs TA, Pazhenkottil AP, Nkoulou RN, et al. Diagnostic value of ${ }^{13} \mathrm{~N}$-ammonia myocardial perfusion PET: added value of myocardial flow reserve. J Nucl Med. 2012;53:1230-4.

120. Morton G, Chiribiri A, Ishida M, Hussain ST, Schuster A, Indermuehle A, et al. Quantification of absolute myocardial perfusion in patients with coronary artery disease: comparison between cardiovascular magnetic resonance and positron emission tomography. J Am Coll Cardiol. 2012;60:1546-55.

121. Anagnostopoulos C, Almonacid A, El Fakhri G, Curillova Z, Sitek A, Roughton M, et al. Quantitative relationship between coronary vasodilator reserve assessed by ${ }^{82} \mathrm{Rb}$ PET imaging and coronary artery stenosis severity. Eur J Nucl Med Mol Imaging. 2008;35:1593-601.

122. Naya M, Murthy VL, Foster CR, Gaber M, Klein J, Hainer J, et al. Prognostic interplay of coronary artery calcification and underlying vascular dysfunction in patients with suspected coronary artery disease. J Am Coll Cardiol. 2013;61:2098-106.

123. Naya M, Murthy VL, Taqueti VR, Foster CR, Klein J, Garber M, et al. Preserved coronary flow reserve effectively excludes highrisk coronary artery disease on angiography. J Nucl Med. 2014;55: $248-55$.

124. Ziadi MC, Dekemp RA, Williams KA, Guo A, Chow BJ, Renaud $\mathrm{JM}$, et al. Impaired myocardial flow reserve on rubidium-82 positron emission tomography imaging predicts adverse outcomes in patients assessed for myocardial ischemia. J Am Coll Cardiol. 2011;58:740-8

125. Danad I, Raijmakers PG, Appelman YE, Harms HJ, de Haan S, van den Oever ML, et al. Coronary risk factors and myocardial blood flow in patients evaluated for coronary artery disease: a quantitative $\left[{ }^{15} \mathrm{O}\right] \mathrm{H}_{2} \mathrm{O}$ PET/CT study. Eur J Nucl Med Mol Imaging. 2012;39:102-12.

126. Danad I, Raijmakers PG, Appelman YE, Harms HJ, de Haan S, Marques KM, et al. Quantitative relationship between coronary artery calcium score and hyperemic myocardial blood flow as assessed by hybrid ${ }^{15} \mathrm{O}$-water PET/CT imaging in patients evaluated for coronary artery disease. J Nucl Cardiol. 2012;19:256-64.

127. Joutsiniemi E, Saraste A, Pietilä M, Mäki M, Kajander S, Ukkonen $\mathrm{H}$, et al. Absolute flow or myocardial flow reserve for the detection of significant coronary artery disease? Eur Heart J Cardiovasc Imaging. 2014;15:659-65.

128. Bom MJ, van Diemen PA, Driessen RS, Everaars H, Schumacher SP, Wijmenga JT, et al. Prognostic value of $\left[{ }^{15} \mathrm{O}^{\mathrm{H}} \mathrm{H}_{2} \mathrm{O}\right.$ positron emission tomography-derived global and regional myocardial perfusion. Eur Heart J Cardiovasc Imaging. 2019. https://doi.org/10. 1093/ehjci/jez258.

129. Klocke FJ, Baird MG, Lorell BH, Bateman TM, Messer JV, Berman DS, et al. ACC/AHA/ASNC guidelines for the clinical use of cardiac radionuclide imaging-executive summary: a report of the American College of Cardiology/American Heart Association Task Force on Practice Guidelines (ACC/AHA/ ASNC Committee to revise the 1995 Guidelines for the Clinical Use of Cardiac Radionuclide Imaging). J Am Coll Cardiol. 2003;42:1318-33.

130. Di Carli MF, Dorbala S, Meserve J, El Fakhri G, Sitek A, Moore SC. Clinical myocardial perfusion PET/CT. J Nucl Med. 2007;48: 783-93.

131. Mc Ardle BA, Dowsley TF, deKemp RA, Wells GA, Beanlands RS. Does rubidium-82 PET have superior accuracy to SPECT perfusion imaging for the diagnosis of obstructive coronary disease?: a systematic review and meta-analysis. J Am Coll Cardiol. 2012;60:1828-37.

132. Bateman TM, Heller GV, McGhie AI, Friedman JD, Case JA, Bryngelson JR, et al. Diagnostic accuracy of rest/stress ECG- gated Rb-82 myocardial perfusion PET: comparison with ECGgated Tc-99m sestamibi SPECT. J Nucl Cardiol. 2006;13:24-33.

133. Stewart RE, Schwaiger M, Molina E, Popma J, Gacioch GM, Kalus M, et al. Comparison of rubidium- 82 positron emission tomography and thallium-201 SPECT imaging for detection of coronary artery disease. Am J Cardiol. 1991;67:1303-10.

134. Yoshinaga K, Chow BJ, Williams K, Chen L, deKemp RA, Garrard L, et al. What is the prognostic value of myocardial perfusion imaging using rubidium- 82 positron emission tomography? J Am Coll Cardiol. 2006;48:1029-39.

135. Hyafil F, Chequer R, Sorbets E, Estellat C, Ducrocq G, Rouzet F, et al. Head-to-head comparison of the diagnostic performances of rubidium-PET and SPECT with CZT camera for the detection of myocardial ischemia in a population of women and overweight individuals. J Nucl Cardiol. 2018. https://doi.org/10.1007/s12350018-01557-z

136. Parkash R, deKemp RA, Ruddy TD, Kitsikis A, Hart R, Beauchesne L, et al. Potential utility of rubidium 82 PET quantification in patients with 3-vessel coronary artery disease. J Nucl Cardiol. 2004;11:440-9.

137. deKemp RA, Yoshinaga K, Beanlands RS. Will 3-dimensional PET-CT enable the routine quantification of myocardial blood flow? J Nucl Cardiol. 2007;14:380-97.

138. Murthy VL, Naya M, Foster CR, Hainer J, Gaber M, Di Carli G, et al. Improved cardiac risk assessment with noninvasive measures of coronary flow reserve. Circulation. 2011;124:2215-24.

139. Dorbala S, Di Carli MF, Beanlands RS, Merhige ME, Williams BA, Veledar E, et al. Prognostic value of stress myocardial perfusion positron emission tomography: results from a multicenter observational registry. J Am Coll Cardiol. 2013;61:176-84.

140. Nohara R, Kambara H, Kawai C, Yonekura Y, Senda M, Saji H, et al. Exercise ${ }^{13} \mathrm{NH}_{3}$-positron emission computed tomography (PET) versus exercise single photon emission computed tomography (SPECT). J Cardiogr Suppl. 1987;12:107-16.

141. Muzik O, Duvernoy C, Beanlands RS, Sawada S, Dayanikli F, Wolfe ER Jr, et al. Assessment of diagnostic performance of quantitative flow measurements in normal subjects and patients with angiographically documented coronary artery disease by means of nitrogen-13 ammonia and positron emission tomography. J Am Coll Cardiol. 1998;31:534-40.

142. Czernin J, Barnard RJ, Sun KT, Krivokapich J, Nitzsche E, Dorsey D, et al. Effect of short-term cardiovascular conditioning and low-fat diet on myocardial blood flow and flow reserve. Circulation. 1995;92:197-204.

143. Baller D, Notohamiprodjo G, Gleichmann U, Holzinger J, Weise $\mathrm{R}$, Lehmann J. Improvement in coronary flow reserve determined by positron emission tomography after 6 months of cholesterollowering therapy in patients with early stages of coronary atherosclerosis. Circulation. 1999;99:2871-5.

144. Quinones MJ, Hernandez-Pampaloni M, Schelbert H, BulnesEnriquez I, Jimenez X, Hernandez G, et al. Coronary vasomotor abnormalities in insulin-resistant individuals. Ann Intern Med. 2004; $140: 700-8$.

145. Schindler TH, Cadenas J, Facta AD, Li Y, Olschewski M, Sayre J, et al. Improvement in coronary endothelial function is independently associated with a slowed progression of coronary artery calcification in type 2 diabetes mellitus. Eur Heart J. 2009;30: 364-73.

146. Schindler TH, Campisi R, Dorsey D, Prior JO, Olschewski M, Sayre J, et al. Effect of hormone replacement therapy on vasomotor function of the coronary microcirculation in post-menopausal women with medically treated cardiovascular risk factors. Eur Heart J. 2009;30:978-86.

147. Quercioli A, Pataky Z, Vincenti G, Makoundou V, Di Marzo V, Montecucco F, et al. Elevated endocannabinoid plasma levels are 
associated with coronary circulatory dysfunction in obesity. Eur Heart J. 2011;32:1369-78.

148. Quercioli A, Montecucco F, Pataky Z, Thomas A, Ambrosio G, Staub C, et al. Improvement in coronary circulatory function in morbidly obese individuals after gastric bypass-induced weight loss: relation to alterations in endocannabinoids and adipocytokines. Eur Heart J. 2013;34:2063-73.

149. Dorbala S, Hassan A, Heinonen T, Schelbert HR, Di Carli MF. Coronary vasodilator reserve and Framingham risk scores in subjects at risk for coronary artery disease. J Nucl Cardiol. 2006;13: 761-76.

150. Herzog BA, Husmann L, Valenta I, Gaemperli O, Siegrist PT, Tay FM, et al. Long-term prognostic value of ${ }^{13} \mathrm{~N}$-ammonia myocardial perfusion positron emission tomography added value of coronary flow reserve. J Am Coll Cardiol. 2009;54:150-6.

151. Tio RA, Dabeshlim A, Siebelink HM, de Sutter J, Hillege HL, Zeebregts CJ, et al. Comparison between the prognostic value of left ventricular function and myocardial perfusion reserve in patients with ischemic heart disease. J Nucl Med. 2009;50:214-9.

152. Slart RH, Zeebregts CJ, Hillege HL, de Sutter J, Dierckx RA, van Veldhuisen DJ, et al. Myocardial perfusion reserve after a PETdriven revascularization procedure: a strong prognostic factor. J Nucl Med. 2011;52:873-9.

153. Sciagrà R, Passeri $\mathrm{A}$, Bucerius J, Verberne HJ, Slart RH, Lindner $\mathrm{O}$, et al. Clinical use of quantitative cardiac perfusion PET: rationale, modalities and possible indications. Position paper of the Cardiovascular Committee of the European Association of Nuclear Medicine (EANM). Eur J Nucl Med Mol Imaging. 2016;43:1530-45.

154. Dilsizian V, Bacharach SL, Beanlands RS, Bergmann SR, Delbeke D, Dorbala S, et al. ASNC imaging guidelines/SNMMI procedure standard for positron emission tomography (PET) nuclear cardiology procedures. J Nucl Cardiol. 2016;23:1187-226.

155. Murthy VL, Bateman TM, Beanlands RS, Berman DS, BorgesNeto S, Chareonthaitawee P, et al. Clinical quantification of myocardial blood flow using PET: joint position paper of the SNMMI Cardiovascular Council and the ASNC. J Nucl Cardiol. 2018;25: 269-97.

156. Ziadi MC, Dekemp RA, Williams K, Guo A, Renaud JM, Chow $\mathrm{BJ}$, et al. Does quantification of myocardial flow reserve using rubidium-82 positron emission tomography facilitate detection of multivessel coronary artery disease? J Nucl Cardiol. 2012;19:670 80.

157. Murthy VL, Naya M, Taqueti VR, Foster CR, Gaber M, Hainer J, et al. Effects of sex on coronary microvascular dysfunction and cardiac outcomes. Circulation. 2014;129:2518-27.

158. Taqueti VR, Shaw LJ, Cook NR, Murthy VL, Shah NR, Foster $\mathrm{CR}$, et al. Excess cardiovascular risk in women relative to men referred for coronary angiography is associated with severely impaired coronary flow reserve, not obstructive disease. Circulation. 2017;135:566-77.

159. Harnett DT, Hazra S, Maze R, Mc Ardle BA, Alenazy A, Simard $\mathrm{T}$, et al. Clinical performance of Rb-82 myocardial perfusion PET and Tc-99m-based SPECT in patients with extreme obesity. J Nucl Cardiol. 2019;26:275-83.

160. Fukushima K, Javadi MS, Higuchi T, Lautamäki R, Merrill J, Nekolla SG, et al. Prediction of short-term cardiovascular events using quantification of global myocardial flow reserve in patients referred for clinical ${ }^{82} \mathrm{Rb}$ PET perfusion imaging. J Nucl Med. 2011;52:726-32.

161. Farhad H, Dunet V, Bachelard K, Allenbach G, Kaufmann PA, Prior JO. Added prognostic value of myocardial blood flow quantitation in rubidium-82 positron emission tomography imaging. Eur Heart J Cardiovasc Imaging. 2013;14:1203-10.
162. Dorbala S, Di Carli MF. Cardiac PET perfusion: prognosis, risk stratification, and clinical management. Semin Nucl Med. 2014;44:344-57.

163. Neglia D, Michelassi C, Trivieri MG, Sambuceti G, Giorgetti A, Pratali L, et al. Prognostic role of myocardial blood flow impairment in idiopathic left ventricular dysfunction. Circulation. 2002;105:186-93.

164. Majmudar MD, Murthy VL, Shah RV, Kolli S, Mousavi N, Foster $\mathrm{CR}$, et al. Quantification of coronary flow reserve in patients with ischaemic and non-ischaemic cardiomyopathy and its association with clinical outcomes. Eur Heart J Cardiovasc Imaging. 2015;16: 900-9.

165. Cecchi F, Olivotto I, Gistri R, Lorenzoni R, Chiriatti G, Camici PG. Coronary microvascular dysfunction and prognosis in hypertrophic cardiomyopathy. N Engl J Med. 2003;349:1027-35.

166. Castagnoli H, Ferrantini C, Coppini R, Passeri A, Baldini K, Berti $\mathrm{V}$, et al. Role of quantitative myocardial positron emission tomography for risk stratification in patients with hypertrophic cardiomyopathy: a 2016 reappraisal. Eur J Nucl Med Mol Imaging. 2016;43:2413-22.

167. Murthy VL, Naya M, Foster CR, Gaber M, Hainer J, Klein J, et al. Association between coronary vascular dysfunction and cardiac mortality in patients with and without diabetes mellitus. Circulation. 2012;126:1858-68.

168. Murthy VL, Naya M, Foster CR, Hainer J, Gaber M, Dorbala S, et al. Coronary vascular dysfunction and prognosis in patients with chronic kidney disease. JACC Cardiovasc Imaging. 2012;5:102534.

169. Shah NR, Charytan DM, Murthy VL, Skali Lami H, Veeranna V, Cheezum MK, et al. Prognostic value of coronary flow reserve in patients with dialysis-dependent ESRD. J Am Soc Nephrol. 2016;27:1823-9.

170. Monroy-Gonzalez AG, Tio RA, de Groot JC, et al. Long-term prognostic value of quantitative myocardial perfusion in patients with chest pain and normal coronary arteries. J Nucl Cardiol. 2019;26:1844-52.

171. Mc Ardle BA, Davies RA, Chen L, Small GR, Ruddy TD, Dwivedi G, et al. Prognostic value of rubidium- 82 positron emission tomography in patients after heart transplant. Circ Cardiovasc Imaging. 2014;7:930-7.

172. Gould KL, Johnson NP, Kaul S, Kirkeeide RL, Mintz GS, Rentrop KP, et al. Patient selection for elective revascularization to reduce myocardial infarction and mortality: new lessons from randomized trials, coronary physiology, and statistics. Circ Cardiovasc Imaging. 2015;8. https://doi.org/10.1161/ CIRCIMAGING.114.003099.

173. Taqueti VR, Hachamovitch R, Murthy VL, Naya M, Foster CR, Hainer J, et al. Global coronary flow reserve is associated with adverse cardiovascular events independently of luminal angiographic severity and modifies the effect of early revascularization. Circulation. 2015;131:19-27.

174. Siegrist PT, Husmann L, Knabenhans M, Gaemperli O, Valenta I, Hoefflinghaus T, et al. ${ }^{13} \mathrm{~N}$-ammonia myocardial perfusion imaging with a PET/CT scanner: impact on clinical decision making and cost-effectiveness. Eur J Nucl Med Mol Imaging. 2008;35: 889-95.

175. Flotats A, Knuuti J, Gutberlet M, Marcassa C, Bengel FM, Kaufmann PA, et al. Hybrid cardiac imaging: SPECT/CT and $\mathrm{PET} / \mathrm{CT}$. A joint position statement by the European Association of Nuclear Medicine (EANM), the European Society of Cardiac Radiology (ESCR) and the European Council of Nuclear Cardiology (ECNC). Eur J Nucl Med Mol Imaging. 2011;38:201-121.

176. Dorbala S, Di Carli MF, Delbeke D, Abbara S, DePuey EG, Dilsizian $\mathrm{V}$, et al. SNMMI/ASNC/SCCT guideline for cardiac SPECT/CT and PET/CT 1.0. J Nucl Med. 2013;54:1485-507. 
177. Nensa F, Bamberg F, Rischpler C, Menezes L, Poeppel TD, la Fougère $\mathrm{C}$, et al. Hybrid cardiac imaging using PET/MRI: a joint position statement by the European Society of Cardiovascular Radiology (ESCR) and the European Association of Nuclear Medicine (EANM). Eur Radiol. 2018;28:4086-101.

178. Knuuti J, Ballo H, Juarez-Orozco LE, Saraste A, Kolh P, Rutjes AWS, et al. The performance of non-invasive tests to rule-in and rule-out significant coronary artery stenosis in patients with stable angina: a meta-analysis focused on post-test disease probability. Eur Heart J. 2018;39:3322-30.

179. Menke J, Kowalski J. Diagnostic accuracy and utility of coronary CT angiography with consideration of unevaluable results: a systematic review and multivariate Bayesian random-effects metaanalysis with intention to diagnose. Eur Radiol. 2016;26:451-8.

180. Hoffmann U, Ferencik M, Udelson JE, Picard MH, Truong QA, Patel MR, et al. Prognostic value of noninvasive cardiovascular testing in patients with stable chest pain: insights from the PROMISE trial (Prospective Multicenter Imaging Study for Evaluation of Chest Pain). Circulation. 2017;135:2320-32.

181. Cheruvu C, Precious B, Naoum C, Blanke P, Ahmadi A, Soon J, et al. Long term prognostic utility of coronary CT angiography in patients with no modifiable coronary artery disease risk factors: results from the 5 year follow-up of the CONFIRM International Multicenter Registry. J Cardiovasc Comput Tomogr. 2016;10:227.

182. Nielsen LH, Bøtker HE, Sørensen HT, Schmidt M, Pedersen L, Sand NP, et al. Prognostic assessment of stable coronary artery disease as determined by coronary computed tomography angiography: a Danish multicentre cohort study. Eur Heart J. 2016: ehw548.

183. Budoff MJ, Mayrhofer T, Ferencik M, Bittner D, Lee KL, Lu MT, et al. Prognostic value of coronary artery calcium in the PROMISE study (Prospective Multicenter Imaging Study for Evaluation of Chest Pain). Circulation. 2017;136:1993-2005.

184. Thomassen A, Petersen H, Johansen A, Braad PE, Diederichsen AC, Mickley H, et al. Quantitative myocardial perfusion by O-15water PET: individualized vs. standardized vascular territories. Eur Heart J Cardiovasc Imaging. 2015;16:970-6.

185. Montalescot G, Sechtem U, Achenbach S, Andreotti F, Arden C, Budaj A, et al. 2013 ESC guidelines on the management of stable coronary artery disease: the Task Force on the Management of Stable Coronary Artery Disease of the European Society of Cardiology. Eur Heart J. 2013;34:2949-3003.

186. Hecht HS, Cronin P, Blaha MJ, Budoff MJ, Kazerooni EA, Narula J, et al. 2016 SCCT/STR guidelines for coronary artery calcium scoring of noncontrast noncardiac chest CT scans: a report of the Society of Cardiovascular Computed Tomography and Society of Thoracic Radiology. J Thorac Imaging. 2017;32:W54-66.

187. Reyes E, Stirrup J, Roughton M, D’Souza S, Underwood SR, Anagnostopoulos C. Attenuation of adenosine-induced myocardial perfusion heterogeneity by atenolol and other cardioselective beta-adrenoceptor blockers: a crossover myocardial perfusion imaging study. J Nucl Med. 2010;51:1036-43.

188. Kassamali RH, Kim DH, Patel H, Raichura N, Hoey ET, Hodson J, et al. Safety of an i.v. $\beta$-adrenergic blockade protocol for heart rate optimization before coronary CT angiography. AJR Am J Roentgenol. 2014;203:759-62.

189. Gaemperli O, Schepis T, Kalff V, Namdar M, Valenta I, Stefani L, et al. Validation of a new cardiac image fusion software for threedimensional integration of myocardial perfusion SPECT and stand-alone 64-slice CT angiography. Eur J Nucl Med Mol Imaging. 2007;34:1097-106.

190. Manka R, Kuhn FP, Kuest SM, Gaemperli O, Kozerke S, Kaufmann PA. Hybrid cardiac magnetic resonance/computed tomographic imaging: first fusion of three-dimensional magnetic resonance perfusion and low-dose coronary computed tomographic angiography. Eur Heart J. 2011;32:2625.

191. Gould KL, Pan T, Loghin C, Johnson NP, Guha A, Sdringola S. Frequent diagnostic errors in cardiac PET/CT due to misregistration of CT attenuation and emission PET images: a definitive analysis of causes, consequences, and corrections. J Nucl Med. 2007;48:1112-21.

192. Gimelli A, Achenbach S, Buechel RR, Edvardsen T, Francone M, Gaemperli O, et al. Strategies for radiation dose reduction in nuclear cardiology and cardiac computed tomography imaging: a report from the European Association of Cardiovascular Imaging (EACVI), the Cardiovascular Committee of European Association of Nuclear Medicine (EANM), and the European Society of Cardiovascular Radiology (ESCR). Eur Heart J. 2018;39:286-96.

193. Namdar M, Hany TF, Koepfli P, Siegrist PT, Burger C, Wyss CA, et al. Integrated PET/CT for the assessment of coronary artery disease: a feasibility study. J Nucl Med. 2005;46:930-5.

194. Sampson UK, Dorbala S, Limaye A, Kwong R, Di Carli MF. Diagnostic accuracy of rubidium-82 myocardial perfusion imaging with hybrid positron emission tomography/computed tomography in the detection of coronary artery disease. J Am Coll Cardiol. 2007;49:1052-8.

195. Groves AM, Speechly-Dick ME, Kayani I, Pugliese F, Endozo R, McEwan J, et al. First experience of combined cardiac PET/64detector CT angiography with invasive angiographic validation. Eur J Nucl Med Mol Imaging. 2009;36:2027-33.

196. Thomassen A, Petersen H, Diederichsen AC, Mickley H, Jensen LO, Johansen A, et al. Hybrid CT angiography and quantitative ${ }^{15} \mathrm{O}$-water PET for assessment of coronary artery disease: comparison with quantitative coronary angiography. Eur J Nucl Med Mol Imaging. 2013;40:1894-904.

197. Rizvi A, Han D, Danad I, Hartaigh BÓ, Lee JH, Gransar H, et al. Diagnostic performance of hybrid cardiac imaging methods for assessment of obstructive coronary artery disease compared with stand-alone coronary computed tomography angiography: a metaanalysis. JACC Cardiovasc Imaging. 2018;11:589-99.

198. Santana CA, Garcia EV, Faber TL, Sirineni GK, Esteves FP, Sanyal R, et al. Diagnostic performance of fusion of myocardial perfusion imaging (MPI) and computed tomography coronary angiography. J Nucl Cardiol. 2009;16:201-11.

199. Slomka PJ, Cheng VY, Dey D, Woo J, Ramesh A, Van Kriekinge $\mathrm{S}$, et al. Quantitative analysis of myocardial perfusion SPECT anatomically guided by coregistered 64-slice coronary CT angiography. J Nucl Med. 2009;50:1621-30.

200. Gaemperli O, Schepis T, Valenta I, Husmann L, Scheffel H, Duerst V, et al. Cardiac image fusion from stand-alone SPECT and CT: clinical experience. J Nucl Med. 2007;48:696-703.

201. Liga R, Vontobel J, Rovai D, Marinelli M, Caselli C, Pietila M, et al. Multicentre multi-device hybrid imaging study of coronary artery disease: results from the EValuation of INtegrated Cardiac Imaging for the Detection and Characterization of Ischaemic Heart Disease (EVINCI) hybrid imaging population. Eur Heart J Cardiovasc Imaging. 2016;17:951-60.

202. Gräni C, Benz DC, Possner M, Clerc OF, Mikulicic F, Vontobel J, et al. Fused cardiac hybrid imaging with coronary computed tomography angiography and positron emission tomography in patients with complex coronary artery anomalies. Congenit Heart Dis. 2017; 12:49-57.

203. Maaniitty T, Jaakkola S, Saraste A, Knuuti J. Hybrid coronary computed tomography angiography and positron emission tomography myocardial perfusion imaging in evaluation of recurrent symptoms after coronary artery bypass grafting. Eur Heart $\mathrm{J}$ Cardiovasc Imaging. 2018. https://doi.org/10.1093/ehjci/jey160.

204. Stenström I, Maaniitty T, Uusitalo V, Pietilä M, Ukkonen H, Kajander S, et al. Frequency and angiographic characteristics of coronary microvascular dysfunction in stable angina: a hybrid 
imaging study. Eur Heart J Cardiovasc Imaging. 2017;18:120613.

205. Pazhenkottil AP, Nkoulou RN, Ghadri JR, Herzog BA, Buechel RR, Kuest SM, et al. Prognostic value of cardiac hybrid imaging integrating single-photon emission computed tomography with coronary computed tomography angiography. Eur Heart J. 2011;32:1465-71.

206. Maaniitty T, Stenström I, Bax JJ, Uusitalo V, Ukkonen H, Kajander S, et al. Prognostic value of coronary CT angiography with selective PET perfusion imaging in coronary artery disease. JACC Cardiovasc Imaging. 2017;10:1361-70.

207. Pazhenkottil AP, Nkoulou RN, Ghadri JR, Herzog BA, Kuest SM, Husmann L, et al. Impact of cardiac hybrid single-photon emission computed tomography/computed tomography imaging on choice of treatment strategy in coronary artery disease. Eur Heart J. 2011;32:2824-9.

208. Danad I, Raijmakers PG, Harms HJ, van Kuijk C, van Royen N, Diamant $\mathrm{M}$, et al. Effect of cardiac hybrid ${ }^{15} \mathrm{O}$-water PET/CT imaging on downstream referral for invasive coronary angiography and revascularization rate. Eur Heart J Cardiovasc Imaging. 2014;15:170-9.

209. Schepis T, Gaemperli O, Koepfli P, Namdar M, Valenta I, Scheffel $\mathrm{H}$, et al. Added value of coronary artery calcium score as an adjunct to gated SPECT for the evaluation of coronary artery disease in an intermediate-risk population. J Nucl Med. 2007;48: 1424-30.

210. Ghadri JR, Pazhenkottil AP, Nkoulou RN, Goetti R, Buechel RR, Husmann L, et al. Very high coronary calcium score unmasks obstructive coronary artery disease in patients with normal SPECT MPI. Heart. 2011;97:998-1003.

211. Schenker MP, Dorbala S, Hong EC, Rybicki FJ, Hachamovitch R, Kwong RY, et al. Interrelation of coronary calcification, myocardial ischemia, and outcomes in patients with intermediate likelihood of coronary artery disease: a combined positron emission tomography/computed tomography study. Circulation. 2008;117: 1693-700.

212. Assante R, Acampa W, Zampella E, Arumugam P, Nappi C, Gaudieri V, et al. Coronary atherosclerotic burden vs. coronary vascular function in diabetic and nondiabetic patients with normal myocardial perfusion: a propensity score analysis. Eur J Nucl Med Mol Imaging. 2017;44:1129-35.

213. Assante R, Zampella E, Arumugam P, Acampa W, Imbriaco M, Tout D, et al. Quantitative relationship between coronary artery calcium and myocardial blood flow by hybrid rubidium-82 PET/ CT imaging in patients with suspected coronary artery disease. J Nucl Cardiol. 2017;24:494-501.

214. Imbriaco M, Nappi C, Ponsiglione A, Pisani A, Dell'Aversana S, Nicolai E, et al. Hybrid positron emission tomography-magnetic resonance imaging for assessing different stages of cardiac impairment in patients with Anderson-Fabry disease: AFFINITY study group. Eur Heart J Cardiovasc Imaging. 2019. https://doi.org/10. 1093/ehjci/jez039.

215. Nappi C, Altiero M, Imbriaco M, Nicolai E, Giudice CA, Aiello M, et al. First experience of simultaneous PET/MRI for the early detection of cardiac involvement in patients with Anderson-Fabry disease. Eur J Nucl Med Mol Imaging. 2015;42:1025-31.

216. Nensa F, Poeppel TD, Beiderwellen K, Schelhorn J, Mahabadi AA, Erbel R, et al. Hybrid PET/MR imaging of the heart: feasibility and initial results. Radiology. 2013;268:366-73.

217. Rischpler C, Langwieser N, Souvatzoglou M, Batrice A, van Marwick S, Snajberk J, et al. PET/MRI early after myocardial infarction: evaluation of viability with late gadolinium enhancement transmurality vs. 18F-FDG uptake. Eur Heart J Cardiovasc Imaging. 2015;16:661-9.

218. Wicks E, Menezes L, Pantazis A, Mohiddin S, Porter J, Booth H, et al. Novel hybrid positron emission tomography - magnetic resonance (PET-MR) multi-modality inflammatory imaging has improved diagnostic accuracy for detecting cardiac sarcoidosis. Heart. 2014;100:A80.

219. Writing group; Document reading group; EACVI Reviewers: This document was reviewed by members of the EACVI Scientific Documents Committee for 2014-2016 and 2016-2018. A joint procedural position statement on imaging in cardiac sarcoidosis: from the Cardiovascular and Inflammation \& Infection Committees of the European Association of Nuclear Medicine, the European Association of Cardiovascular Imaging, and the American Society of Nuclear Cardiology. Eur Heart J Cardiovasc Imaging. 2017;18:1073-89.

220. Yalamanchili P, Wexler E, Hayes M, Yu M, Bozek J, Kagan M, et al. Mechanism of uptake and retention of ${ }^{18} \mathrm{~F}$ BMS747158-02 in cardiomyocytes: a novel PET myocardial imaging agent. J Nucl Cardiol. 2007;14:782-8.

221. Yu M, Guaraldi MT, Mistry M, Kagan M, McDonald JL, Drew K, et al. BMS-747 158-02: a novel PET myocardial perfusion imaging agent. J Nucl Cardiol. 2007;14:789-98.

222. Huisman M, Higuchi T, Reder S, Nekolla SG, Poethko T, Wester $\mathrm{HJ}$, et al. Initial characterization of an $18 \mathrm{~F}$-labeled myocardial perfusion tracer. J Nucl Med. 2008;49:630-6.

223. Sherif HM, Nekolla SG, Saraste A, Reder S, Yu M, Robinson S, et al. Simplified quantification of myocardial flow reserve with flurpiridaz F 18: validation with microspheres in a pig model. J Nucl Med. 2011;52:617-24.

224. Yu M, Guaraldi M, Kagan M, Mistry M, McDonald J, Bozek J, et al. Assessment of 18F-labeled mitochondrial complex I inhibitors as PET myocardial perfusion imaging agents in rats, rabbits, and primates. Eur J Nucl Med Mol Imaging. 2009;36:63-72.

225. Yu M, Bozek J, Guaraldi M, Kagan M, Azure M, Robinson SP. Cardiac imaging and safety evaluation of BMS747158, a novel PET myocardial perfusion imaging agent, in chronic myocardial compromised rabbits. J Nucl Cardiol. 2010;17:631-6.

226. Maddahi J, Czernin J, Lazewatsky J, Huang SC, Dahlbom M, Schelbert H, et al. Phase I, first-in-human study of BMS747158, a novel F-18 labeled tracer for myocardial perfusion PET imaging: dosimetry, biodistribution, safety, and imaging characteristics after a single injection at rest. J Nucl Med. 2011;52:1490-8.

227. Maddahi J, Bengel F, Czernin J, Crane P, Dahlbom M, Schelbert $\mathrm{H}$, et al. Dosimetry, biodistribution, and safety of flurpiridaz F18 in healthy subjects undergoing 2-day rest-stress PET myocardial perfusion imaging. J Nucl Cardiol. 2019;26:2018-30. https://doi. org/10.1007/s12350-018-01484-z.

228. Berman DS, Maddahi J, Tamarappoo BK, Czernin J, Taillefer R, Udelson JE, et al. Phase II safety and clinical comparison with single-photon emission computed tomography myocardial perfusion imaging for detection of coronary artery disease: flurpiridaz $\mathrm{F}$ 18 positron emission tomography. J Am Coll Cardiol. 2013;61: 469-77.

229. Moody JB, Poitrasson-Rivière A, Hagio T, Buckley C, Weinberg $\mathrm{RL}$, Corbett JR, et al. Added value of myocardial blood flow using ${ }^{18}$ F-flurpiridaz PET to diagnose coronary artery disease: the Flurpiridaz 301 Trial. J Nucl Cardiol. 2020. https://doi.org/10. 1007/s12350-020-02034-2.

Publisher's note Springer Nature remains neutral with regard to jurisdictional claims in published maps and institutional affiliations. 